\title{
The surface aerosol optical properties in the urban area of Nanjing, west Yangtze River Delta, China
}

\author{
Bingliang Zhuang ${ }^{1}$, Tijian Wang ${ }^{1}$, Jane Liu ${ }^{1,2}$, Shu Li ${ }^{1}$, Min Xie ${ }^{1}$, Yong Han ${ }^{1}$, Pulong Chen ${ }^{1}$, Qiduo Hu${ }^{1}$, \\ Xiu-qun Yang ${ }^{1}$, Congbin $\mathrm{Fu}^{1}$, and Jialei $\mathrm{Zhu}^{3}$ \\ ${ }^{1}$ School of Atmospheric Sciences, CMA-NJU Joint Laboratory for Climate Prediction Studies, Jiangsu Collaborative \\ Innovation Center for Climate Change, Nanjing University, Nanjing 210023, China \\ ${ }^{2}$ Department of Geography and Planning, University of Toronto, Toronto, M5S 3G3, Canada \\ ${ }^{3}$ Department of Climate and Space Sciences and Engineering, University of Michigan, Ann Arbor, Michigan, USA
}

Correspondence to: Bingliang Zhuang (blzhuang@nju.edu.cn) and Tijian Wang (tjwang@nju.edu.cn)

Received: 18 May 2016 - Published in Atmos. Chem. Phys. Discuss.: 8 August 2016

Revised: 15 December 2016 - Accepted: 4 January 2017 - Published: 25 January 2017

\begin{abstract}
Observational studies of aerosol optical properties are useful for reducing uncertainties in estimations of aerosol radiative forcing and forecasting visibility. In this study, the observed near-surface aerosol optical properties in urban Nanjing are analysed from March 2014 to February 2016. Results show that near-surface urban aerosols in Nanjing are mainly from local emissions and the surrounding regions. They have lower loadings but are more scattering than aerosols in most cities in China. The annual mean aerosol extinction coefficient (EC), single-scattering albedo (SSA) and asymmetry parameter (ASP) at $550 \mathrm{~nm}$ are $381.96 \mathrm{Mm}^{-1}$, 0.9 and 0.57 , respectively. The aerosol absorption coefficient (AAC) is about 1 order of magnitude smaller than its scattering coefficient (SC). However, the absorbing aerosol has a larger Ångström exponent (AAE) value, 1.58 at 470/660 nm, about 0.2 larger than the scattering aerosols (SAE). All the aerosol optical properties follow a near-unimodal pattern, and their values are mostly concentrated around their averages, accounting for more than $60 \%$ of the total samplings. Additionally, they have substantial seasonality and diurnal variations. High levels of SC and AAC all appear in winter due to higher aerosol and trace gas emissions. AAE (ASP) is the smallest (largest) in summer, possibly because of high relative humidity $(\mathrm{RH})$ which also causes considerably larger SC and smaller SAE, although intensive gas-toparticle transformation could produce a large number of finer scattering aerosols in this season. Seasonality of EC is different from the columnar aerosol optical depth. Larger AACs appear during the rush hours of the day while SC and back-
\end{abstract}

scattering coefficient (Bsp) only peak in the early morning. Aerosols are fresher in the daytime than at night-time, leading to their larger Ångström exponent and smaller ASP. Different temporal variations between AAC and SC cause the aerosols to be more absorbing (smaller SSA) in autumn, winter and around rush hours. ASP has a good quasi-log-normal growth trend with increasing SC when RH is below $60 \%$. The correlation between AAC and SC at the site is close but a little smaller than that in suburban Nanjing in spring. Atmospheric visibility decreases exponentially with increasing EC or SC, more sharply in spring and summer, and it could be further deteriorated with increasing SSA and ASP.

\section{Introduction}

Atmospheric aerosols have substantial influences on human health, air quality and climate changes and their loadings have significantly increased since the preindustrial times (Qin et al., 2001; Forster et al., 2007). Due to their ability to scatter/absorb solar radiation and act as cloud condensation nuclei, atmospheric aerosols can affect atmospheric radiation and dynamics, as well as the Earth's hydrologic cycle, leading to regional or global climate changes (Forster et al., 2007; Rosenfeld et al., 2008; Qian et al., 2009; Li et al., 2011; Wang et al., 2014; Guo et al., 2016a). Light-scattering aerosols have contributed to offsetting the warming effect of $\mathrm{CO}_{2}$ (Kiehl and Briegleb, 1993) while light-absorbing aerosols such as black carbon (BC) could further enhance global warming 
(Jacobson 2002), especially in the high aerosol regions. Due to the warming effect of $\mathrm{BC}$, the atmosphere would become more unstable, which might result in changes in the trend of precipitation in China over the past decades as suggested by Menon et al. (2002). Furthermore, atmospheric aerosols can be a major component of haze pollution, altering atmospheric visibility and being harmful to human health (Chameides and Bergin, 2002).

Observations and modelling studies have been conducted on aerosol optical properties and radiative forcing, as well as its climate effects on regional and global scales in the past two decades (e.g. Penner et al., 2001; Bellouin et al., 2003; Liao and Seinfeld, 2005; Yan et al., 2008; Wu et al., 2012; Zhuang et al., 2013a, 2014a; Wang et al., 2015; Yu et al., 2016). Forster et al. (2007) summarized that large uncertainties exist in estimating the aerosol radiative forcing, especially in climate models. The bias mostly results from the uncertainties in the simulated aerosol optical properties (Holler et al., 2003), which, in turn, are related to the aerosol loadings, profiles, compositions, mixing states and atmospheric humidity. The 5th IPCC reported that the global mean direct radiative forcing ranged from -0.85 to $+0.15 \mathrm{~W} \mathrm{~m}^{-2}$ for total aerosols and from +0.05 to $+0.8 \mathrm{~W} \mathrm{~m}^{-2}$ for $\mathrm{BC}$ (IPCC, 2013). This would further lead to much larger uncertainties in the estimations of the aerosol climate effects. In east Asia, the range of simulated $\mathrm{BC}$ direct radiative forcing is much larger than the global one, varying from +0.32 to $+0.81 \mathrm{~W} \mathrm{~m}^{2}$ (Zhuang et al., 2013a). The uncertainty could be substantially reduced in a model if the aerosol optical properties are based on observations or if observed properties are directly used (Forster et al., 2007).

In the last three decades, China has experienced the most rapid economic growth worldwide. This leads to high emissions of anthropogenic aerosols and trace gases (e.g. Guo et al., 2009; Zhang et al., 2009; Xin et al., 2014; Che et al., 2015). The anthropogenic aerosol emissions in east Asia were estimated to exceed 1/4 of the global emissions (Streets et al., 2001), resulting in more diversified aerosol compositions, complex species and heterogeneous spatial distributions in the region (Zhang et al., 2012), especially in megacities and urban agglomerations (e.g. Beijing-TianjinHebei (BTH), Yangtze River Delta (YRD) and Pearl River Delta (PRD) regions). Uncertainties of the aerosol radiative forcing and corresponding climate effects in these regions might be much larger than those of the rest of the world (e.g. Forster et al., 2007; Zhuang et al., 2013b). In addition, the diurnal variability of aerosol properties has been suggested due to other major factors leading to such large biases (e.g. $\mathrm{Xu}$ et al., 2016). Therefore, it is necessary to characterize the aerosol optical properties based on observations in China, as many studies did in recent years at urban sites and in rural areas (e.g. Bergin et al., 2001; Xu et al., 2002, 2004, 2012; Zhang et al., 2004, 2015; Yan, 2006; Xia et al., 2007; Li et al., 2007; Yan et al., 2008; Andreae et al., 2008; He et al., 2009; Wu et al., 2009, 2012; Wang et al., 2009; Li et al.,
2010; Fan et al., 2010; Bai et al., 2011; Cai et al., 2011; Xiao et al., 2011; Zhuang et al., 2015; Li et al., 2015a, b; Yu et al., 2016). For example, Bergin et al. (2001), He et al. (2009) and Zhuang et al. (2015) presented the surface aerosol scattering and absorption properties in urban area of north and east China and they suggested that the annual mean $532 \mathrm{~nm}$ AAC (aerosol absorption coefficient) in Beijing was about $56 \mathrm{Mm}^{-1}$ and it was $41-44 \mathrm{Mm}^{-1}$ in YRD, which were much smaller than those in central to south-west China and in PRD (Wu et al., 2009; Cao et al., 2012; Tao et al., 2014) but much larger than those in rural and desert regions (Xu et al., 2002, 2004; Yan et al., 2008). In addition to surface measurements, the columnar optical properties of the aerosols were also observed (Xia et al., 2007; Zhuang et al., 2014a; Che et al., 2015). Long-term measurements of the country-wide aerosol optical depths and Ångström exponents in China from 2002 to 2013 were introduced by Che et al. (2015). In spite of intensive observation-based studies, measurements and analyses on aerosol properties in the YRD region, one of the most populous regions in China, are still rather limited. To fill the gaps in the current observational network in China and to better understand the optical properties of urban aerosols in YRD, this study will analyse the observations of aerosol scattering (SC), back-scattering (Bsp), absorption (AAC), extinction (EC) coefficients and singlescattering albedo (SSA), Ångström exponent of scattering (SAE) and absorbing (AAE) aerosols, as well as aerosol asymmetry parameter (ASP) in the urban area of Nanjing, a major megacity in YRD. Our ultimate goals are to provide a reference when estimating aerosol radiative forcing and climate effect as well as forecasting visibility.

In the following, the method is described in Sect. 2. Results and discussions are presented in Sect. 3, followed by conclusions in Sect. 4.

\section{Data and methodologies}

\subsection{Sampling station and instruments}

The sampling station is located at the Gulou campus of Nanjing University, urban area of Nanjing $\left(32.05^{\circ} \mathrm{N}, 118.78^{\circ} \mathrm{E}\right)$. It is built on the roof of a $79.3 \mathrm{~m}$-tall building, around which there are no industrial pollution sources within a $30 \mathrm{~km} \mathrm{ra}$ dius but there are several main roads with apparent traffic pollution, especially at rush hours. The layout of the site and the corresponding climatology have been described in Zhu et al. (2012).

The wavelength-dependent $\mathrm{AAC}$ and concentrations of $\mathrm{BC}$ were derived from the measurements using a sevenchannel Aethalometer (model AE-31, Magee Scientific, USA). The wavelength-dependent aerosol SC and Bsp were measured using a three-wavelength-integrating Nephelometer (Aurora 3000, Australia). To make a brief comparison between surface and column aerosols, the wavelength- 
dependent columnar aerosol optical depth (AOD) was observed using a Cimel sunphotometer (CE-318). The AE-31 model measures light attenuation at seven wavelengths, including $370,470,520,590,660,880$ and $950 \mathrm{~nm}$, with a desired flow rate of $5.0 \mathrm{~L} \mathrm{~min}^{-1}$ and a sampling interval of $5 \mathrm{~min}$. Aurora 3000 measures aerosol light scattering, including SC and Bsp at 450,525 and $635 \mathrm{~nm}$, with a sampling interval of 1 min. CE-318 measures the AOD from 340 to $1640 \mathrm{~nm}$ in the daytime. Routine calibrations and maintenances were carried out for all these instruments during the sampling periods. R-134 was used as a span gas for Aurora 3000 . The aerosol inlet is located about $1 \mathrm{~m}$ above the roof. Data to be analysed in this study were measured from March 2014 to February 2016 for AE-31 and CE-318 and from June 2014 to February 2016 for Aurora 3000. Meteorological data (such as relative humidity) during the sampling period are from the National Meteorological Station of Nanjing (no. 58238).

\subsection{Calculation of the aerosol optical properties}

The wavelength-dependent aerosol absorption coefficient (AAC) and BC mass concentration can be calculated directly based on the measured light attenuations (ATN) through a quartz filter matrix (Petzold et al., 1997; Weingartner et al., 2003; Arnott et al., 2005; Schmid et al., 2006):

$\sigma_{\mathrm{ATN}, t}(\lambda)=\frac{\left(\operatorname{ATN}_{t}(\lambda)-\operatorname{ATN}_{t-1}(\lambda)\right)}{\Delta t} \times \frac{A}{V}$,

where $A\left(\right.$ in $^{2}$ ) is the area of the aerosol-laden filter spot, $V$ is the volumetric sampling flow rate (in $\mathrm{L} \mathrm{min}^{-1}$ ) and $\Delta t$ is the time interval $\left(=5 \mathrm{~min}\right.$ ) between $t$ and $t-1 . \sigma_{\mathrm{ATN}}$ is the AAC without any correction, which is generally larger than the actual one ( $\left.\sigma_{\text {abs }}\right)$ because of the optical interactions of the filter substrate with the deposited aerosol. Generally, there are two key factors leading to the bias: (1) multiple scattering of light at the filter fibres (multiple-scattering effect) and (2) instrumental response with increased particle loading on the filter (shadowing effect). Thus, the correction is needed and the calibration factors $C$ and $R$ (shown in Eq. 2) are introduced against the scattering effect and shadowing effect, respectively:

$\sigma_{\mathrm{abs}, t}(\lambda)=\frac{\sigma_{\mathrm{ATN}, t}(\lambda)}{C \times R}$.

Collaud Coen et al. (2010) suggested that AAC corrected from Weingartner et al. (2003) (WC2003 for short, hereinafter) and Schmid et al. (2006) (SC2006 for short, hereinafter) have good agreements with the one measured by a Multi-Angle Absorption Photometer. These two corrections are similar to each other and they use the same $R(\lambda)$ :

$R_{t}(\lambda)=\left(\frac{1}{f}-1\right) \times \frac{\ln \left(\operatorname{ATN}_{t}(\lambda)\right)-\ln 10}{\ln 50-\ln 10}+1$, where $R=1$ when ATN $\leq 10$ and $f=1.2$. However, $C$ is fixed in WC2003 but is wavelength-dependent in SC2006. According to $\mathrm{Wu}$ et al. (2013) and Zhuang et al. (2015), $C$ in Nanjing is 3.48 in WC2003 while it is 2.95, 3.37, $3.56,3.79,3.99,4.51$ and 4.64 at 370, 470, 520, 590, 660, 880 and $950 \mathrm{~nm}$ in SC2006. Zhuang et al. (2015) further suggested that wavelength-dependent AACs corrected by SC2006 might be closer to the real ones than WC2003s in Nanjing, although $532 \mathrm{~nm}$ AACs from these two corrections are close to each other. In addition to the direct method, AAC can be calculated indirectly:

$\sigma_{\mathrm{abs}, t}(\lambda)=[\mathrm{BC}] \times \gamma$,

where $[\mathrm{BC}]$ is the mass concentration of Aethalometer $\mathrm{BC}$ (in $\mu \mathrm{g} \mathrm{m}^{-3}$ ) without any correction and $\gamma$ is the conversion factor determined empirically from linear regression of the Aethalometer BC concentration versus the aerosol absorption measurement (Yan et al., 2008). Zhuang et al. (2015) indicated that $\gamma$ from the linear regression of the Aethalometer $\mathrm{BC}$ concentrations $\left(\mathrm{ng} \mathrm{m}^{3}\right)$ at $880 \mathrm{~nm}$ against the light absorption coefficient $\left(\mathrm{Mm}^{-1}\right)$ at $532 \mathrm{~nm}$ in Nanjing is about $11.05 \mathrm{~m}^{2} \mathrm{~g}^{-1}$. It is obvious that only $532 \mathrm{~nm}$ AAC can be addressed from this way. Thus, AACs corrected from SC2006 are used in this study.

Based on wavelength-dependent AAC and SC, Ångström exponent of scattering (SAE) and absorbing (AAE) aerosols are estimated by the following:

$$
\begin{aligned}
\mathrm{AAE}_{470 / 660 \mathrm{~nm}} & = \\
& -\log \left(\mathrm{AAC}_{470 \mathrm{~nm}} / \mathrm{AAC}_{660 \mathrm{~nm}}\right) / \log (470 / 660) \\
\mathrm{SAE}_{450 / 635 \mathrm{~nm}} & = \\
& -\log \left(\mathrm{SC}_{450 \mathrm{~nm}} / \mathrm{SC}_{635 \mathrm{~nm}}\right) / \log (450 / 635) .
\end{aligned}
$$

For purposes of comparison, AAC at 450, 525, 532, 550 and $635 \mathrm{~nm}, \mathrm{SC}$ at 532 and $550 \mathrm{~nm}$ as well as Bsp at 532 and $550 \mathrm{~nm}$ were further calculated by the given coefficients and corresponding Ångström exponents:

$\sigma_{\lambda}=\sigma_{\lambda_{0}} \times\left(\frac{\lambda}{\lambda_{0}}\right)^{-\alpha}$,

where $\sigma_{\lambda}$ is the coefficient at wavelength $\lambda$ and $\alpha$ is the corresponding Ångström exponents.

Based on wavelength-dependent SC, Bsp, AAC, aerosol asymmetry parameter (ASP), single-scattering albedo (SSA) and extinction coefficient (EC) are further estimated:

$$
\begin{aligned}
& \mathrm{ASP}_{\lambda}=-7.143889 \beta_{\lambda}^{3}+7.46443 \beta_{\lambda}^{2}-3.9356 \beta_{\lambda}+0.9893 \\
& \mathrm{SSA}_{\lambda}=\frac{\mathrm{SC}_{\lambda}}{\mathrm{SC}_{\lambda}+\mathrm{AAC}_{\lambda}} \\
& \mathrm{EC}_{\lambda}=\mathrm{SC}_{\lambda}+\mathrm{AAC}_{\lambda},
\end{aligned}
$$

where $\beta_{\lambda}$ is the ratio of $\mathrm{Bsp}$ to $\mathrm{SC}$ at wavelength $\lambda$. Equation (8) is derived from Andrews et al. (2006). 
Table 1. Statistical summary of the surface aerosol optical properties in Nanjing.

\begin{tabular}{|c|c|c|c|c|}
\hline Factors & Max & Min & Mean \pm SD & Median \\
\hline $550 \mathrm{~nm}$ AAC $\left(\mathrm{Mm}^{-1}\right)$ & 230.648 & 1.439 & $29.615 \pm 20.454$ & 24.572 \\
\hline $550 \mathrm{~nm} \mathrm{SC}\left(\mathrm{Mm}^{-1}\right)$ & 2493.092 & 20.673 & $338.275 \pm 228.078$ & 284.379 \\
\hline $550 \mathrm{~nm} \operatorname{Bsp}\left(\mathrm{Mm}^{-1}\right)$ & 300.101 & 1.401 & $44.257 \pm 27.396$ & 38.206 \\
\hline $550 \mathrm{~nm} \mathrm{EC}\left(\mathrm{Mm}^{-1}\right)$ & 2643.101 & 31.186 & $381.958 \pm 252.271$ & 321.679 \\
\hline $550 \mathrm{~nm} \mathrm{SSA}$ & 0.988 & 0.404 & $0.901 \pm 0.049$ & 0.908 \\
\hline $550 \mathrm{~nm}$ ASP & 0.908 & 0.118 & $0.571 \pm 0.088$ & 0.582 \\
\hline $470 / 660 \mathrm{~nm}$ AAE & 3.256 & 0.145 & $1.583 \pm 0.228$ & 1.592 \\
\hline $450 / 635 \mathrm{~nm} \mathrm{SAE}$ & 3.344 & 0.162 & $1.320 \pm 0.407$ & 1.317 \\
\hline
\end{tabular}

AAC: aerosol absorption coefficient. SC: aerosol scattering coefficient.

Bsp: aerosol back-scattering coefficient. SSA: aerosol single-scattering albedo.

ASP: aerosol asymmetry parameter. AAE: Ångström exponent of absorbing aerosols.

SAE: Angström exponent of scattering aerosols.

\section{Results and discussions}

It is well known that the temporal variations of the aerosol optical properties at different wavelengths are generally consistent with each other. Therefore, only single-wavelength (such as $550 \mathrm{~nm}$ ) AAC, SC, Bsp, SSA and ASP are focused when analysing their basic characteristics (including temporal variations, frequency distributions and changes with wind direction), their relationships with each other and their relationships with the meteorological conditions (such as RH and VIS) and columnar AOD.

\subsection{Temporal variations of the aerosol optical properties}

The aerosol absorption coefficient (AAC) was directly obtained from the measurement of AE-31 and the scattering and back-scattering coefficients (SC and Bsp), which were directly measured from Aurora 3000. Based on wavelength-dependent $\mathrm{AAC}$ and $\mathrm{SC}$, the Ångström exponent of absorbing (AAE at $470 / 660 \mathrm{~nm}$ ) and scattering (SAE at $450 / 635 \mathrm{~nm}$ ) aerosols were estimated according to Eqs. (5) and (6). Based on AAC, SC and Bsp, wavelengthdependent aerosol asymmetry parameter (ASP), singlescattering albedo (SSA) and extinction coefficient (EC) are further estimated using Eqs. 8-10 and analysed. Table 1 lists the statistical summary of surface aerosol optical properties in the urban area of Nanjing during the sampling period. The annual mean AAC, SC, Bsp, EC, SSA and ASP at $550 \mathrm{~nm}$, $\mathrm{AAE}$ at $470 / 660 \mathrm{~nm}$ and $\mathrm{SAE}$ at $450 / 635 \mathrm{~nm}$ are 29.615 , $338.275,44.257,381.958 \mathrm{Mm}^{-1}, 0.901,0.571,1.583$ and 1.320 , with a standard deviation of $20.454,228.078,27.396$ and $252.271 \mathrm{Mm}^{-1}, 0.049,0.088,0.228$ and 0.407 , respectively.

Figure 1 shows the 10th, 25th, median, 75th and 90th percentile values of the $550 \mathrm{~nm}$ AAC, SC, Bsp, 470/660 nmAAE and $450 / 635 \mathrm{~nm}-\mathrm{SAE}$ in the urban area of Nanjing in each season from March 2014 to February 2016. Default values of aerosol scattering properties in spring 2014 are blank because the measurements of Aurora 3000 started from June 2014. The figure suggests that AAC, SC, Bsp, AAE and SAE have substantially seasonal variations. A high level of AAC appears in winter (DJF) while a lower level is found in summer (JJA) (Fig. 1a). The temporal variability of Bsp is similar to that of AAC (Fig. 1d). According to Zhang et al. (2009), emissions of the aerosols and trace gases in China are larger in winter than in other seasons, especially for carbonaceous aerosols (Fig. 1c in Zhuang et al., 2013b). Thus, the higher $A A C$ values in winter than in summer might result from the higher aerosol emissions, lower boundary height (Guo et al., 2016b) and less rainfall. However, possibly due to the impacts of hygroscopic growth of aerosol caused by higher $\mathrm{RH}$ in summer and dust aerosol in spring (Zhuang et al., 2014a), $\mathrm{SC}$ is considerably large in these two seasons (Fig. 1c). Thus, the lowest SC is found in autumn in both 2014 and 2015. AAE has a similar seasonality to AAC. Due to relatively higher RH, a small value of AAE is found in JJA while the larger ones appear in the other seasons (Fig. 1b), which is different from the seasonality of SAE. SAE is larger in warmer seasons but is smaller in the other seasons. Scattering aerosols, including inorganic and partially organic components, mainly come from gas-to-particle transformation, so that they have smaller sizes (larger AE) compared to the primary aerosols (such as dust and BC). The efficiency of gasto-particle transformation is higher in warmer seasons. The observations of the aerosol compositions at the site showed that seasonal mean inorganic aerosols, including sulfate, nitrate and ammonium, account for about $50 \%$ of the total $\mathrm{PM}_{2.5}$ in spring and might be higher than $50 \%$ in the other seasons (Zhuang et al., 2014b). Thus, SAE in summer and autumn is large (Fig. 1e). RH can impose substantial influences on scattering aerosols. SAE might be much larger than the current values in these two seasons if the hygroscopic growth were excluded. Seasonal mean RH is about 75.41 and $70.86 \%$ in JJA and SON, respectively, to a certain degree leading to higher values of SAE in autumn than in summer. The figure also suggests that the aerosol absorption coeffi- 
Table 2. Seasonal mean \pm SD of the surface aerosol optical properties in Nanjing.

\begin{tabular}{|c|c|c|c|c|}
\hline Factors & MAM & JJA & SON & DJF \\
\hline $550 \mathrm{~nm}$ AAC $\left(\mathrm{Mm}^{-1}\right)$ & $26.954 \pm 18.632$ & $19.653 \pm 15.689$ & $33.474 \pm 19.686$ & $37.958 \pm 21.892$ \\
\hline $550 \mathrm{~nm} \mathrm{SC}\left(\mathrm{Mm}^{-1}\right)$ & $318.998 \pm 202.264$ & $340.865 \pm 226.151$ & $294.624 \pm 200.052$ & $385.137 \pm 255.282$ \\
\hline $550 \mathrm{~nm} \operatorname{Bsp}\left(\mathrm{Mm}^{-1}\right)$ & $42.995 \pm 23.580$ & $36.990 \pm 25.067$ & $38.684 \pm 23.017$ & $54.786 \pm 30.974$ \\
\hline $550 \mathrm{~nm} \mathrm{EC}\left(\mathrm{Mm}^{-1}\right)$ & $341.279 \pm 209.315$ & $370.236 \pm 248.125$ & $351.887 \pm 244.267$ & $422.569 \pm 273.565$ \\
\hline $550 \mathrm{~nm} \mathrm{SSA}$ & $0.915 \pm 0.043$ & $0.933 \pm 0.049$ & $0.874 \pm 0.053$ & $0.890 \pm 0.040$ \\
\hline $550 \mathrm{~nm}$ ASP & $0.553 \pm 0.086$ & $0.638 \pm 0.069$ & $0.566 \pm 0.079$ & $0.540 \pm 0.083$ \\
\hline 470/660 nm AAE & $1.571 \pm 0.172$ & $1.488 \pm 0.263$ & $1.524 \pm 0.277$ & $1.701 \pm 0.156$ \\
\hline 450/635 nm SAE & $1.097 \pm 0.320$ & $1.337 \pm 0.428$ & $1.544 \pm 0.352$ & $1.235 \pm 0.383$ \\
\hline
\end{tabular}

cient and scattering coefficient as well as their sizes in 2014 are higher than in 2015. The observed RH difference in these 2 years at least partly accounts for the variation of aerosol absorption coefficient and scattering coefficient as well as their sizes. A comparison of RH between 2014 and 2015 indicates that $\mathrm{RH}$ is 79.49 and $72.86 \%$ in JJA and SON, respectively, in 2014, larger than in $2015(71.33 \%$ in JJA and 69.03 in SON).

Figure 2 plots the seasonal mean values with standard deviations of AAC, SC, Bsp, EC, SSA, ASP, AAE at $470 / 660 \mathrm{~nm}$ and SAE at 450/635 nm. AAC, SC, Bsp and EC increase with decreasing wavelength in four seasons. Changes in SSA and ASP with increasing wavelength are different in different seasons. SSA increases with increasing wavelength in colder seasons but much less in JJA and SON. ASP increases with wavelength in JJA, contrary to in other seasons. The figure also suggests that seasonal variation of EC is more consistent with SCs, with large values in JJA and DJF (370.236 and $422.569 \mathrm{Mm}^{-1}$ at $\left.550 \mathrm{~nm}\right)$. The largest values of SSA and ASP appear in JJA (0.933 and 0.638 at $550 \mathrm{~nm}$ ), implying that aerosols in the urban area of Nanjing are more scattering and have a stronger forward-scattering ability in JJA than in other seasons. The urban aerosols are more absorbent in SON and DJF in Nanjing (550 nm SSA is no more than 0.89 ). The seasonal variation of SSA is determined by the variations of both AAC and SC. As mentioned above, AAC is highest in winter and lowest in summer, to a great degree due to the seasonality of the emissions. SC would have the same variation as AAC if only emissions were taken into account. Zhang et al. (2009) indicates that the emission seasonality of carbonaceous aerosols are much stronger than the trace gases ( such $\mathrm{SO}_{2}$ and $\mathrm{NO}_{x}$ ), and they show that the anthropogenic emission rate in winter is about 1.87 times that in summer for black carbon but only about 1.2 for $\mathrm{SO}_{2}$ in China. This is also supported by Sun et al. (2015), who found that the concentration of black carbon aerosol in north China was much higher in winter due to enhanced emissions based on 1-year observations. Thus, the different emission seasonal variations between black carbon and trace gases alone would cause a lower SSA in winter compared to that in summer. What is more, both a higher efficiency of gas- to-particle transformation and higher level of RH in summer are in favour of a much larger SC, which to a certain degree could further enlarge SSA in summer. The smaller SSA in the colder season might mainly be caused by a higher emission of absorbing aerosol.

Seasonal mean $550 \mathrm{~nm}$ AAC, SC, Bsp, EC, SSA and ASP, $470 / 660 \mathrm{~nm}$ AAE and 450/635 nm SAE as well as corresponding standard deviations are listed in Table 2. It suggests that seasonal mean $550 \mathrm{~nm}$ AAC, SC, Bsp, EC, SSA and ASP vary from 19.65 to $37.96,294.62$ to $385.14,36.99$ to 54.79 and 341.3 to $422.57 \mathrm{Mm}^{-1}, 0.874$ to 0.933 and 0.54 to 0.64 , respectively. Seasonal mean AAE and SAE vary from 1.49 to 1.70 and 1.1 to 1.54 , respectively. AAC and Bsp in DJF are about 2 and 1.5 times of those in JJA, respectively. SSA in JJA is about $6.75 \%$ larger than in SON.

In addition to seasonality, the aerosol optical properties near the surface at urban Nanjing have substantial diurnal variations (Fig. 3), especially for the coefficients (AAC, SC, $\mathrm{Bsp}$ and EC). The diurnal variation of $\mathrm{EC}$, which is consistent with SC, is not shown in the figure. AAC levels are usually high at the rush hours around 07:00-09:00 LT and around 09:00-11:00 LT but low in the afternoon (Fig. 3a). At 08:00 LT, mean $550 \mathrm{~nm}$ AAC is about as large as $34 \mathrm{Mm}^{-1}$, while at 02:00, it is about $23 \mathrm{Mm}^{-1}$. SC and Bsp (Fig. 3b, c), to some extent, have diurnal variations similar to AACs. Their lowest values also appear in the afternoon (about $280 \mathrm{Mm}^{-1}$ for SC and $38 \mathrm{Mm}^{-1}$ for Bsp). However, only one peak of the aerosol scattering coefficient is found in the early morning (about $379 \mathrm{Mm}^{-1}$ for Sc and $48 \mathrm{Mm}^{-1}$ for Bsp) and it is about $1-2 \mathrm{~h}$ earlier than its absorption coefficient, possibly owing to the different emissions between these two types of aerosols. Absorbing aerosols in urban Nanjing mainly come from the vehicle emissions because of the developed transportation network, resulting in two peaks of AAC within 1 day (Zhuang et al., 2015). Scattering aerosol loadings are somewhat less affected by traffic emissions, especially at night-time. Their precursors, such as $\mathrm{SO}_{2}$ and NOx, mostly come from coal combustion and industrial emissions in urban Nanjing based on source apportionment. Therefore, there is no peak for SC or Bsp before midnight, although their values are considerably large (about 350 and $46 \mathrm{Mm}^{-1}$ ). Different 
Table 3. The dominant and maximum frequencies as well as corresponding ranges of the aerosol optical properties.

\begin{tabular}{llr|lr}
\hline \multirow{2}{*}{$\begin{array}{l}\text { The aerosol optical } \\
\text { properties }\end{array}$} & \multicolumn{2}{c|}{ The dominant } & \multicolumn{2}{c}{ The maximum } \\
\cline { 2 - 5 } & Bins & Frequencies & Bins & Frequencies \\
\hline AAC & $9-45 \mathrm{Mm}^{-1}$ & $73 \%$ & $9-21 \mathrm{Mm}^{-1}$ & $32.9 \%$ \\
SC & $60-390 \mathrm{Mm}^{-1}$ & $67 \%$ & $170-280 \mathrm{Mm}^{-1}$ & $24.04 \%$ \\
Bsp & $15-60 \mathrm{Mm}^{-1}$ & $69 \%$ & $30-45 \mathrm{Mm}^{-1}$ & $26.45 \%$ \\
SSA & $0.87-0.97$ & $73 \%$ & $0.91-0.93$ & $18.64 \%$ \\
AAE & $1.4-1.8$ & $71 \%$ & $1.5-1.6$ & $20.9 \%$ \\
SAE & $0.96-1.68$ & $62 \%$ & $1.32-1.5$ & $18.06 \%$ \\
ASP & $0.48-0.69$ & $81 \%$ & $0.55-0.62$ & $34 \%$ \\
\hline
\end{tabular}

diurnal cycles between AAC and SC were also observed in the suburban area of Nanjing (Yu et al., 2016). Diurnal variations of AAC, SC and Bsp might be highly affected by the diurnal cycles of the boundary layer. The small coefficients in the afternoon are mostly induced by a well-developed mixing layer (Zhuang et al., 2014b). Generally, the boundary layer becomes more and more stable after sunset and its height lowers, which is conducive to the accumulation of air pollutants at night-time, especially during the period from midnight to sunrise. Therefore, SC usually peaks in early morning and the peak appears at different times in different seasons (05:00 LT in JJA and 08:00-09:00 LT in DJF). The daytime peak of AAC appears at 07:00 LT in JJA and at 09:00 LT in DJF. The diurnal variation of SSA also reflects the difference between AAC and SC (Fig. 3d), implying that aerosols in urban Nanjing are more scattering after midnight (SSA is about 0.91 ) but more absorbing before noon and midnight (SSA is about 0.89). Scattering aerosols mainly come from strong chemical production (gas-to-particle transformation) in the daytime, which to some extent might offset the dilution effect of the boundary on SC, thus leading to a relatively larger SSA in the afternoon. The figure further shows that both AAE (Fig. 3e) and SAE (Fig. 3f) in the daytime are slightly larger than those after midnight because both absorbing and scattering aerosols are fresher in the daytime whereas they are more aged before sunrise. Diurnal variations of SAE and AAE are relatively weaker compared to the corresponding coefficients. In addition to aerosol loadings, the level of Bsp is also affected by the size of the aerosols, as suggested by Yu et al. (2016), and so is ASP (Fig. 3g). The diurnal cycle of ASP is similar to that of Bsp but is opposite to that of SAE. A large ASP appears in the early morning (0.587) and the lower ASP in the afternoon (0.552).

\subsection{Frequencies of the aerosol optical properties}

The frequency of the aerosol optical properties is presented in Fig. 4 and Table 3. Similarly, the frequency of EC is not shown in the figure because it has similar pattern to SCs. Almost all of them follow a unimodal pattern. As listed in Table 3, the dominant ranges for all the aerosol optical prop- erties are distributed around their annual mean values with different widths and they account for at least $60 \%$ of the total samplings during the entire study period. The maximum frequencies of $32.9 \%$ (AAC), $24.04 \%$ (SC), $26.45 \%$ (Bsp), $18.64 \%$ (SSA), $20.9 \%$ (AAE), $18.06 \%$ (SAE) and $34 \%$ (ASP) occur in the ranges from 9 to 21,170 to 280 and 30 to $45 \mathrm{Mm}^{-1}, 0.91$ to $93,1.5$ to $1.6,1.32$ to 1.5 and 0.55 to 0.62 , respectively. Frequency distributions of the aerosol optical properties have substantially seasonal variations. The frequency peaks of the properties would be more concentrated at lower/higher ranges if their seasonal means are smaller/larger. As shown in Fig. 4a, c and e, relatively larger values or the peaks of frequencies for AAC, Bsp and AAE are concentrated in lower value ranges in JJA but in higher value ranges in the other seasons. Moisture absorption growth of absorbing aerosols leads to a leftward shift in an AAE frequency curve in JJA. Effects of dust aerosol also might result in a leftward shift in a SC frequency curve in spring (Fig. 4f). Furthermore, due to dust and RH, SC is considerably large in MAM and JJA, leading to relatively larger frequencies of SC distributed at larger SC ranges compared with the ones of AAC. As mentioned above, aerosols in urban Nanjing are more scattering and have a stronger forwardscattering ability in JJA than in the other seasons, thus larger frequencies occur more at higher-value ranges of SSA and ASP in JJA.

\subsection{Aerosol optical properties in different wind directions}

The east Asian monsoon is active in midlatitudes. Nanjing could be affected by the east Asian summer monsoon in JJA and by the winter monsoon in DJF. Airflows in these two seasons are significantly different (Fig. 5a, b), altering the aerosol optical properties in different seasons. Air masses mostly come from the oceans (about $77 \%$ ) in JJA and from continental regions in the north and north-west of China $(57 \%)$ in DJF. Only a few percentages of air masses are from the northern region of China in JJA. Additionally, considerable air masses arriving at the site are from the local areas (cluster 1 in JJA) or from places near Nanjing (cluster 1 in 


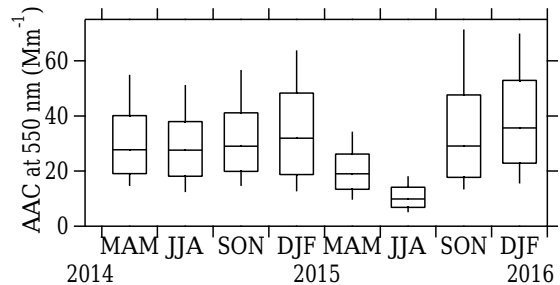

(a)

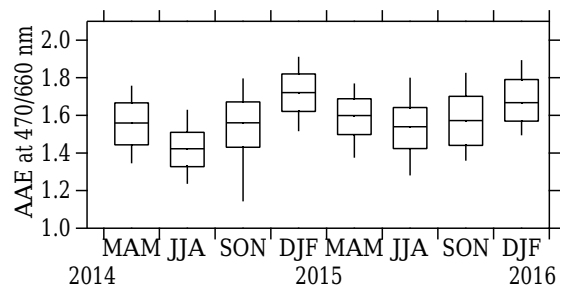

(b)

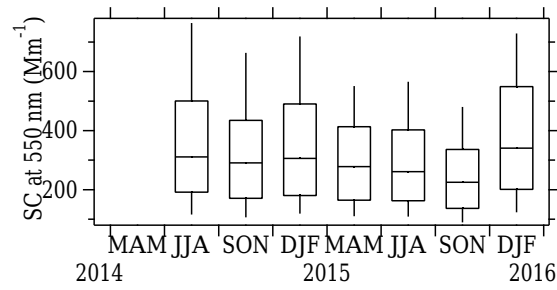

(c)

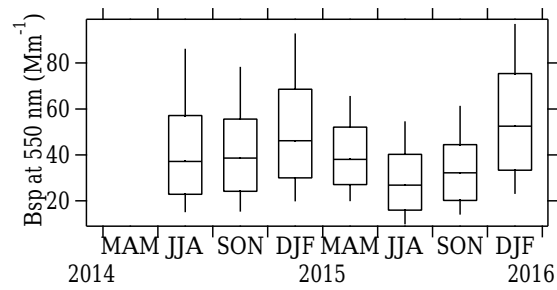

(d)

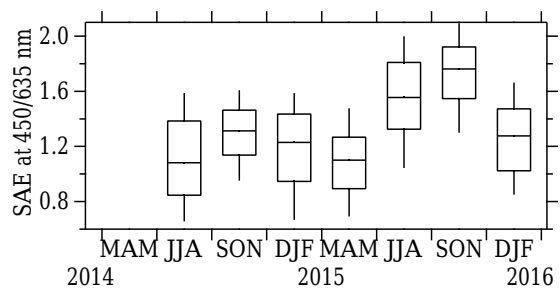

(e)

Figure 1. The 10th, 25th, median, 75th and 90th percentiles of $550 \mathrm{~nm}$ AAC $\left(\mathbf{a}, \mathrm{Mm}^{-1}\right), 470 / 660 \mathrm{~nm} \operatorname{AAE}(\mathbf{b}), 550 \mathrm{~nm}$ SC (c, $\left.\mathrm{Mm}^{-1}\right), 550 \mathrm{~nm}\left(\mathbf{d}, \mathrm{Mm}^{-1}\right)$ and 450/635 nm SAE (e) in each season from March 2014 to February 2016.

DJF). Therefore, the aerosol optical properties at the study site are characterized differently with different air masses in the two seasons.

As suggested by Zhuang et al. (2014b), high BC loadings in early June 2012 were observed at the site in Nanjing when the air masses were from a north-westerly direction, in which serious biomass burning was detected. There-

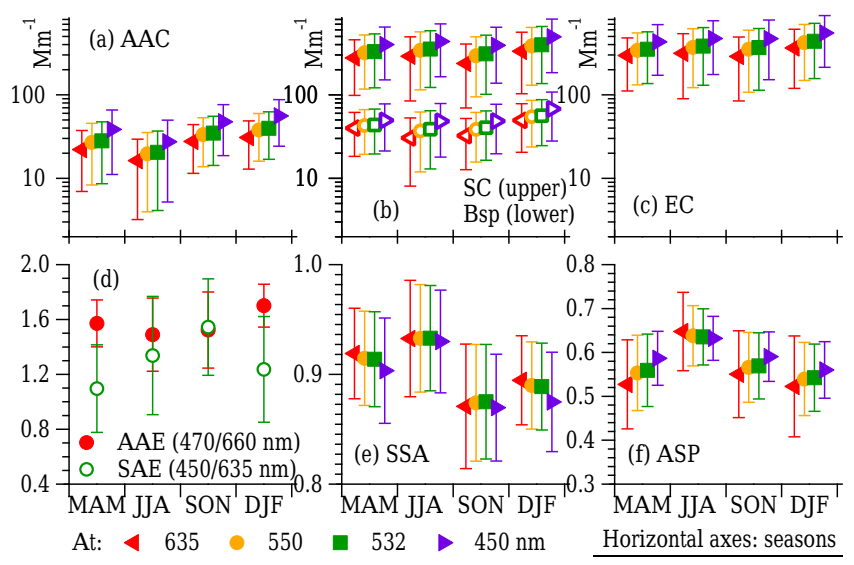

Figure 2. Seasonal means (markers) and corresponding standard deviations (error bars) of wavelength-dependent AAC $\left(\mathbf{a}, \mathrm{Mm}^{-1}\right)$, $\mathrm{SC}$ (b, solid mark, $\left.\mathrm{Mm}^{-1}\right)$, Bsp (b, open mark, $\left.\mathrm{Mm}^{-1}\right)$, EC (c, $\mathrm{Mm}^{-1}$ ), SSA (e) and ASP (f) at 450, 532, 550, $635 \mathrm{~nm}$, as well as AAE at $470 / 660 \mathrm{~nm}$ (d, red solid mark) and SAE at $450 / 635 \mathrm{~nm}$ (d, green open mark).

fore, the aerosol optical properties are further analysed by their origins in both JJA and DJF (Fig 5c, d). In JJA, seasonal mean AAC, SC, Bsp, SSA, ASP, AAE and SAE are about $19.65,340.87$ and $36.99 \mathrm{Mm}^{-1}, 0.93,0.64,1.49$ and 1.34 , respectively (Table 2 ). The dominant air masses are from local areas (cluster 1 in Fig. 5a) and the East China Sea (passing through urban agglomeration regions (cluster 2) and less-developed regions (cluster 3) of the Yangtze River Delta YRD), accounting for $90 \%$ of the total characteristics of the aerosol optical properties in urban Nanjing. All the values of the properties in the first three clusters are closer to their season means. Aerosol absorption and scattering coefficients from local emissions are larger than those in the other clusters. Although air masses in cluster 2 and cluster 3 come from the oceans and have the same level of relative humidity $(\mathrm{RH})$, differences still exist between the clusters. The air masses have to cross the urban agglomeration (from Shanghai to Nanjing) of YRD when they arrive in Nanjing in cluster 2 but past less-developed regions (north Jiangsu Province) in cluster 3. In YRD, emissions of the aerosols and trace gases are much stronger in urban agglomeration regions than those in other areas as suggested in Zhang et al. (2009) and Zhuang et al. (2013b). Therefore, AAC and SC in cluster 2 are larger than in cluster 3 to some extent (Fig. 5a, c). Aerosols from these two clusters are more scattering than the local ones. There are two clusters (cluster 4 and 5 in Fig. 5a) from the remote areas in JJA. Aerosol loadings are relatively small when the air masses come from these two clusters. The size of the aerosols is finer (larger AAE in cluster 5 and SAE in cluster 4 and 5 in Fig. 5c). ASP varying with the clusters coincides with RH varying with the clusters (Fig. 5c), implying that RH might influence ASP significantly. In DJF, seasonal mean AAC, SC, Bsp, SSA, ASP, AAE and SAE are about 

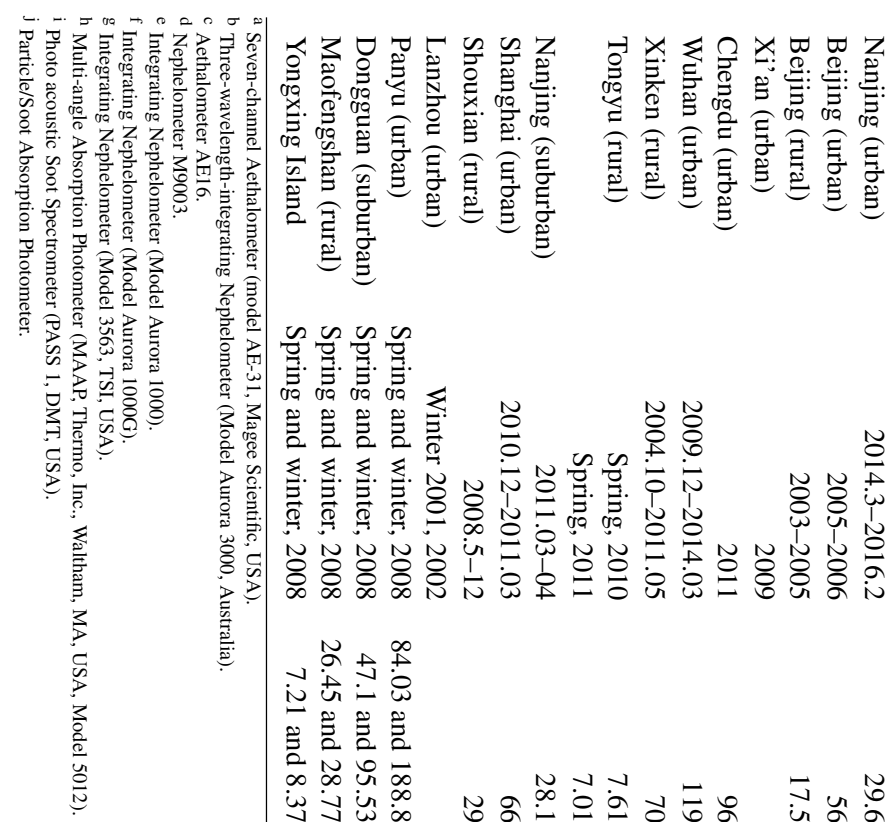

कृष्?

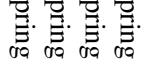

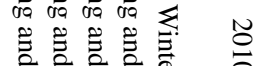

กั

乡. 乡.

ब.

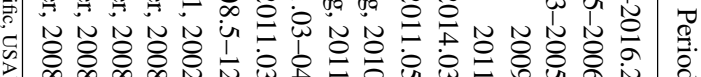

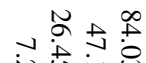

芯言芒

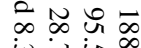

نَّ

岕矛岕岕

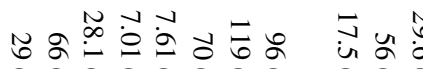

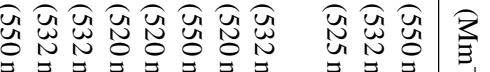

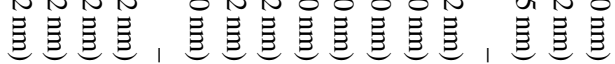

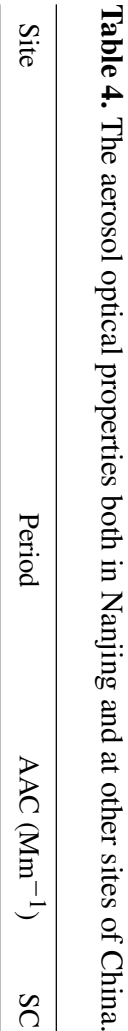

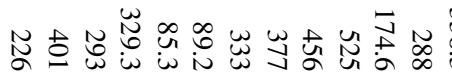

तิ

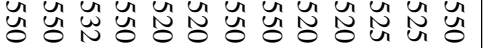

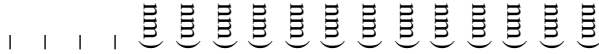

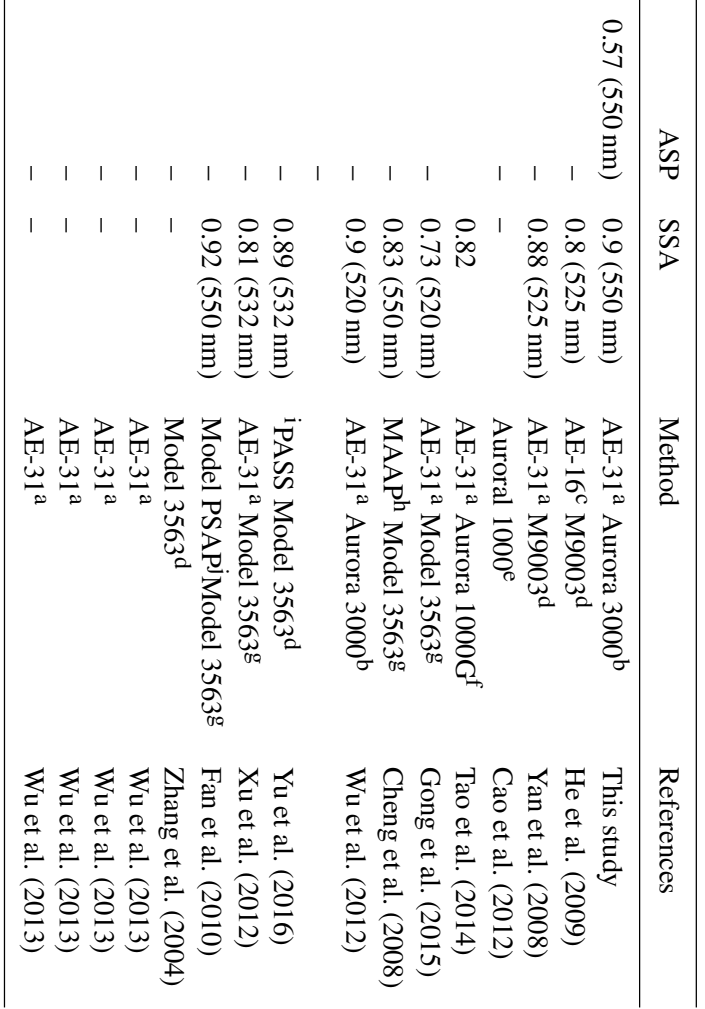



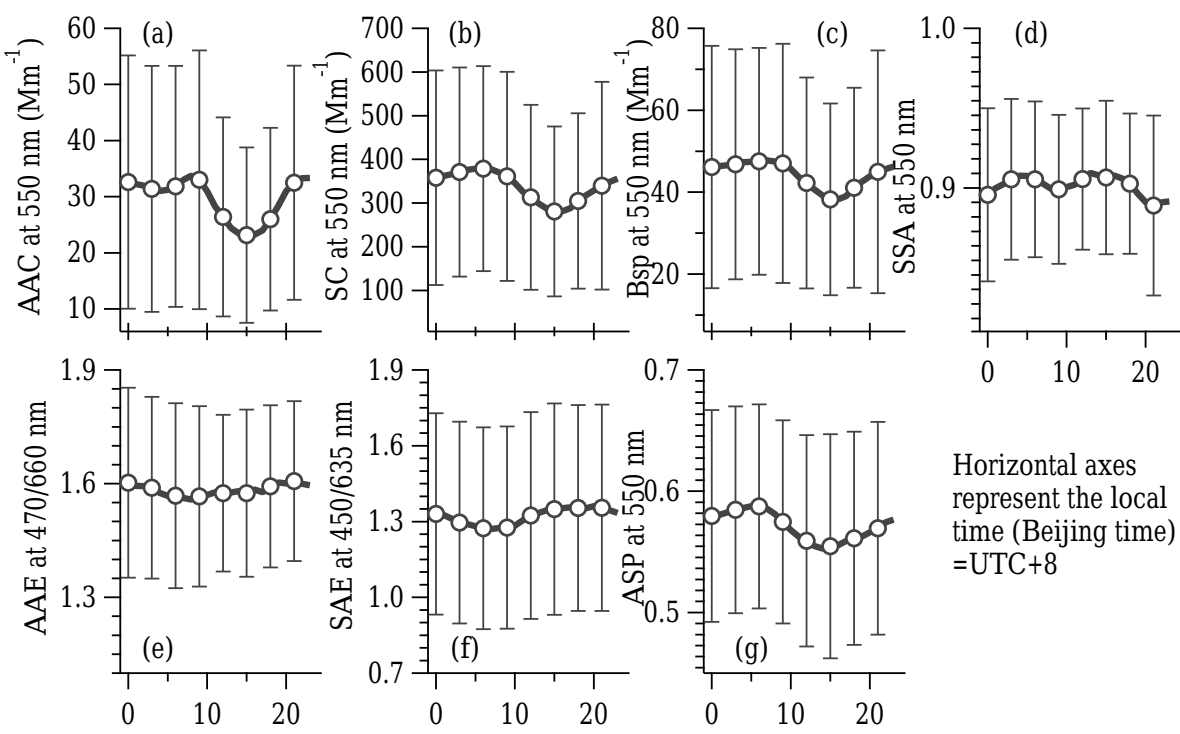

Horizontal axes represent the local time (Beijing time) $=\mathrm{UTC}+8$

Figure 3. Diurnal variations of $550 \mathrm{~nm}$ AAC $\left(\mathbf{a}, \mathrm{Mm}^{-1}\right), \mathrm{SC}\left(\mathbf{b}, \mathrm{Mm}^{-1}\right), \mathrm{Bsp}\left(\mathbf{c}, \mathrm{Mm}^{-1}\right)$, SSA (d), ASP (g), 470/660 nm AAE (e) and $450 / 635 \mathrm{~nm}$ SAE (f) during the study period.
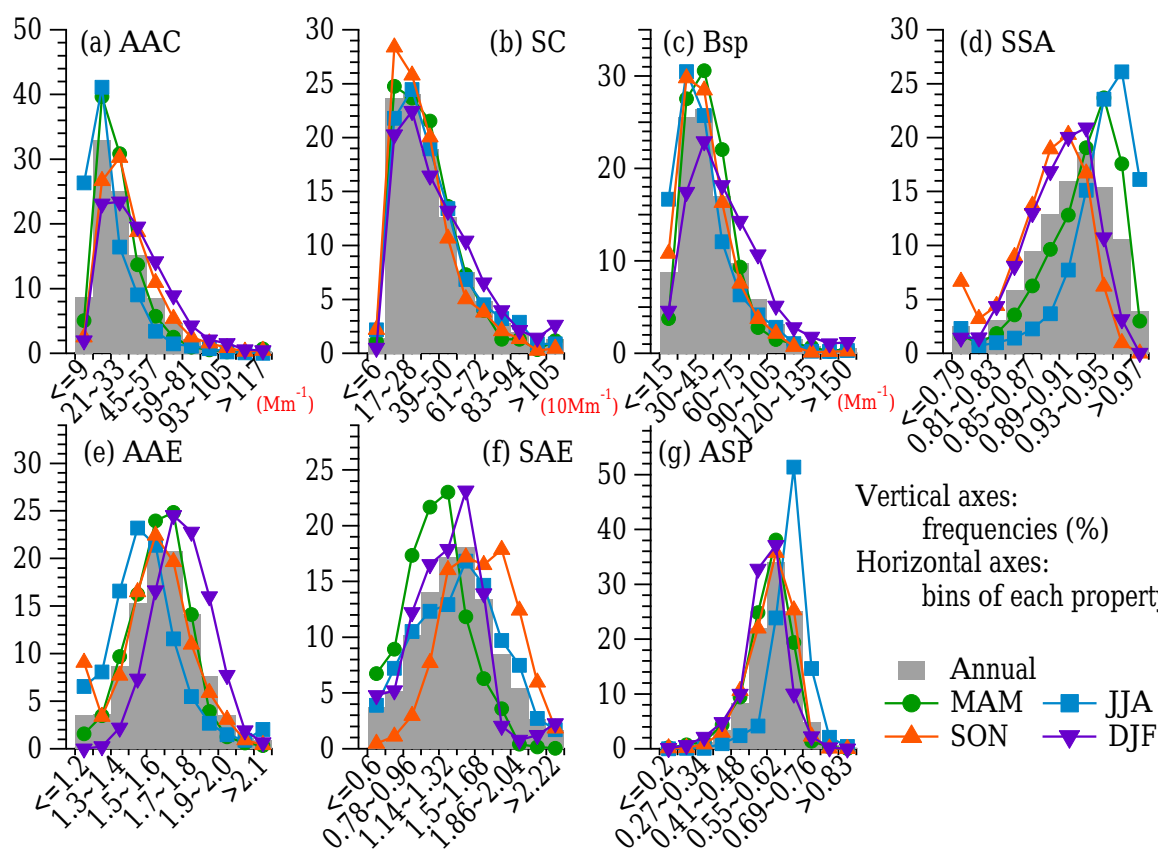

Vertical axes: frequencies (\%)

Horizontal axes:

bins of each property

- Annual

- MAM - JJA

0.0 .0 .06

Figure 4. Frequency (\%) distributions of $550 \mathrm{~nm}$ AAC (a), SC (b), Bsp (c), SSA (d), ASP (g), 470/660 nm AAE (e) and 450/635 nm SAE (f) on annual (shaded bar) and seasonal (coloured marks) scales.

37.96, 385.14 and $54.79 \mathrm{Mm}^{-1}, 0.89,0.54,1.70$ and 1.24 , respectively (Table 2). Similarly to JJA, the aerosol absorption and scattering coefficients are the largest, of which AAC, SC and Bsp are about 1.3 times their seasonal means (Fig. 5d), when the air masses are local or from the regions (cluster 1 in Fig. 5b) near Nanjing in DJF. AAC, SC, Bsp, SSA and ASP are small but AAE and SAE are large if air masses are from remote areas. Aerosols are the smallest, most absorbing and finest when the air masses are from near Lake Baikal. ASP varying with the clusters also coincides with $\mathrm{RH}$ varying with the clusters in this season (Fig. 5d), further implying the effect of RH on ASP.

Substantial studies on aerosol optical properties have been carried out in China from monthly to annual scales. Table 4 lists some annual and seasonal statistics of measured surface aerosol optical properties from literature. Annual and sea- 


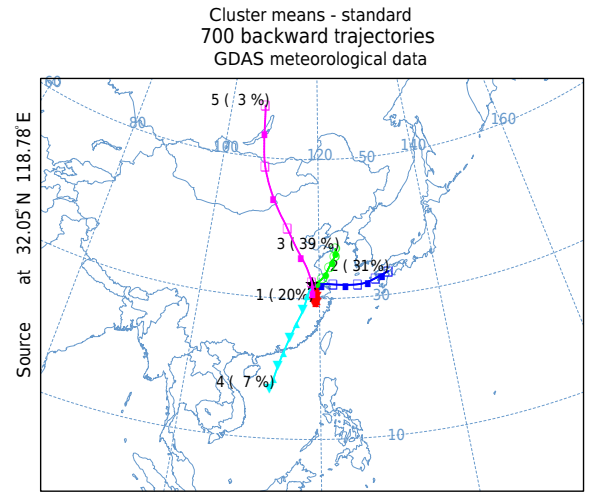

(a)

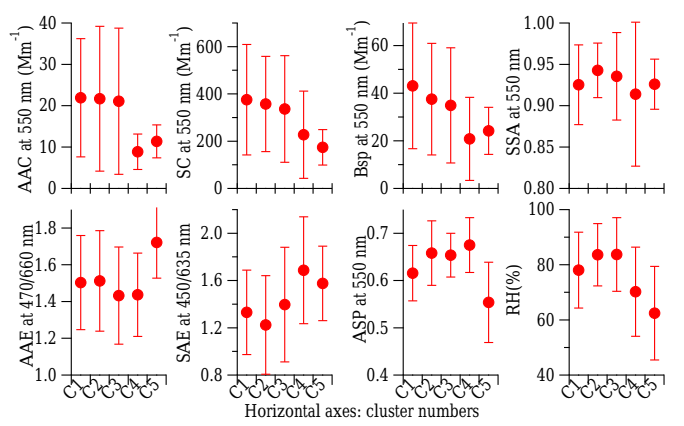

(c)

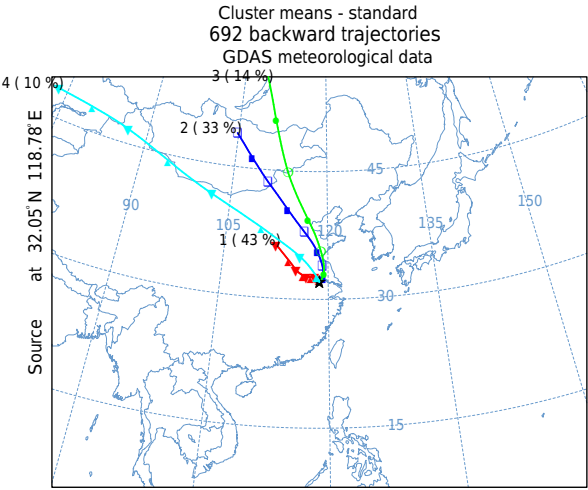

(b)

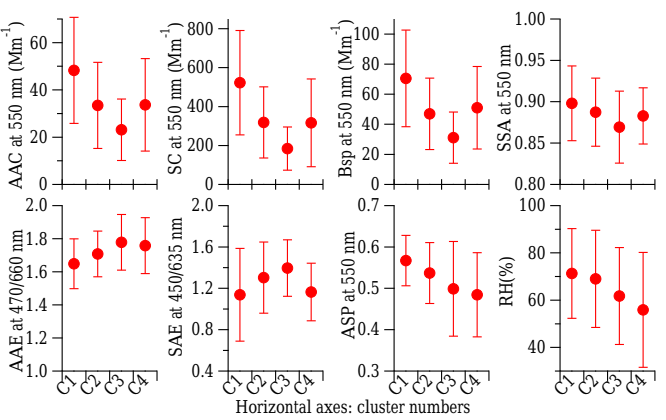

(d)

Figure 5. Clusters of $96 \mathrm{~h}$ back trajectories arriving at the study site at $100 \mathrm{~m}$ in JJA (a) and DJF (b) simulated by the HYSPLIT model. The means with standard deviations of the aerosol optical properties at each cluster of back trajectories in both JJA and DJF are plotted in (c) and (d).

sonal means listed in the table are comparable to some extent, although the observational periods and instruments are different. It suggests that AACs and SCs in urban areas are much higher than those in rural and remote areas. In Beijing (the centre of the Beijing-Tianjin-Hebei region), annual mean AAC and SC were 56 and $288 \mathrm{Mm}^{-1}$ in urban site during the period from 2005 to 2006 (He et al., 2009), which were much larger than the ones $\left(17.5\right.$ and $\left.174.6 \mathrm{Mm}^{-1}\right)$ in rural area (Yan et al., 2008). In Chengdu (Tao et al., 2014), Xi'an (Cao et al., 2012) and Wuhan (Gong et al., 2015), which are in the centre from south-west to central China, the annual mean scattering coefficients in these cities exceeded 450,520 and $370 \mathrm{Mm}^{-1}$, respectively. In the Pearl River Delta (PRD) region, seasonal mean AAC at $532 \mathrm{~nm}$ was about 84 and $188 \mathrm{Mm}^{-1}$ at an urban site (Panyu), about 47 and $95 \mathrm{Mm}^{-1}$ at a suburban site (Dongguan), about 26 and $28 \mathrm{Mm}^{-1}$ at a rural site, and only 7.21 and $8.37 \mathrm{Mm}^{-1}$ at a remote site (Yongxing Island), in spring and winter, respectively (Wu et al., 2013). Additionally, aerosols in urban areas are more absorbing. The aerosol absorptions in urban areas have stronger seasonality than those in rural areas (Table 4). Urban aerosols in Nanjing on an annual scale are somewhat lower but more scattering than in most cities in
China. In addition to annual and seasonal means, there are considerable studies on monthly mean aerosol optical properties (e.g. Bergin et al., 2001; Xu et al., 2002, 2004; Li et al., 2007, 2015a, b; Andreae et al., 2008). A few studies on the aerosol optical properties in Nanjing have been carried out previously (Zhuang et al., 2014a, 2015; Yu et al., 2016) based on observations. They were more focused on the columnar aerosols (Zhuang et al., 2014a), single optical property (Zhuang et al., 2015), or shortening observations (two months in Yu et al., 2016). Here, substantial analyses of the key optical properties of the surface aerosol, to a certain degree, fill the gaps in the studies of aerosols in Nanjing, even in YRD.

\subsection{Relationship among aerosol optical properties, relative humidity and visibility}

The relationships between SC and AAC, and SC and Bsp are presented by season in Fig. 6. As shown in Figs. 3 and 4, these three types of coefficients have similar diurnal and frequency distributions. The linear correlation coefficient varies from 0.93 to 0.97 for SC and Bsp and from 0.66 to 0.87 for SC and AAC in urban Nanjing. It is obvious that relations between SC and Bsp are much better than those between SC 


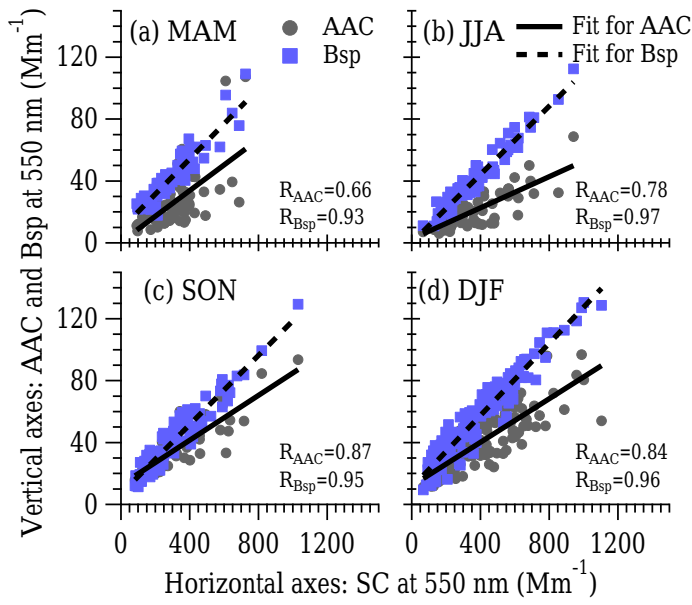

Figure 6. Relationships between $550 \mathrm{~nm} \mathrm{AAC}$ and SC (solids square in blue) and between $550 \mathrm{~nm}$ Bsp and SC (solid cycles in gray) in spring (a), summer (b), autumn (c) and winter (d).

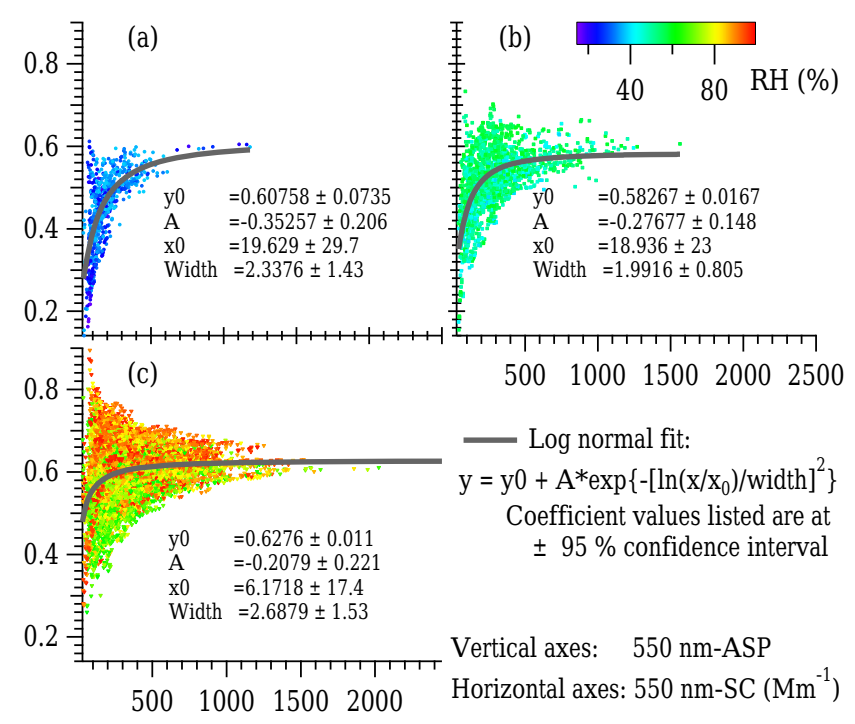

Figure 7. Relationships between the $550 \mathrm{~nm}$ ASP and SC in different RH levels.

and AAC in all seasons. The correlation between AAC and SC becomes poorer in MAM (0.66) and JJA (0.78) because the scattering aerosols are more affected by dust in spring and $\mathrm{SC}$ is more affected by RH in summer. The linear correlation coefficients between $\mathrm{SC}$ and $\mathrm{AAC}$ and between $\mathrm{SC}$ and Bsp in MAM at the site were a little smaller than in suburban Nanjing (Yu et al., 2016) in the same season in 2011. The slope of the fitting between Bsp and SC represents the levels of ASP. Analysis (not shown) suggests that ASP has a significant anti-correlation with the ratio of Bsp to SC (linear $R=-0.98$ ). Thus, a greater slope of curve represents a smaller ASP, thus less forward-scattering of the aerosols.

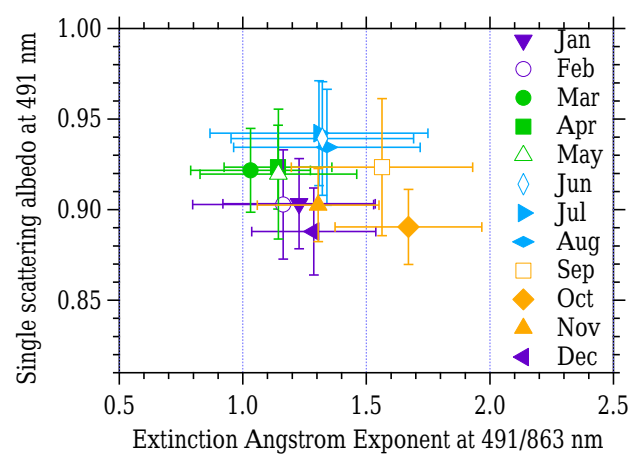

(a)

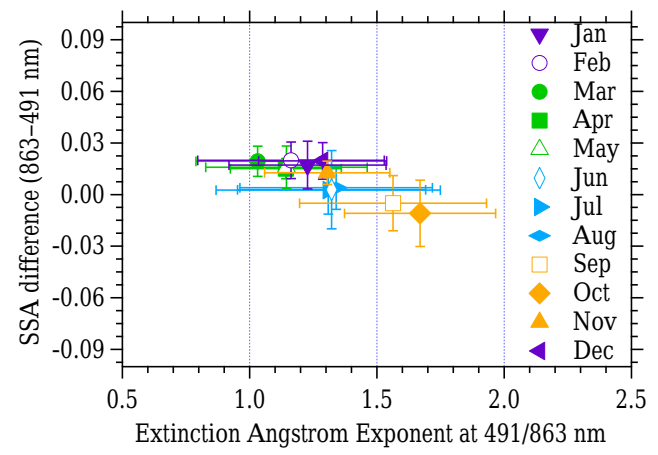

(b)

Figure 8. Relationships between the monthly mean values of $491 \mathrm{~nm}$ SSA and extinction Ångström exponent (EAE) at $491 / 863 \mathrm{~nm}$ (a) and between the monthly mean values of the SSA difference (863-491 nm) and EAE at 491/863 nm (b).

The correlations between ASP and SC under different RH conditions are illustrated in Fig. 7, showing that ASP has a quasi-log-normal distribution with $\mathrm{SC}$, especially in lower RH conditions. ASP increases monotonically with increasing SC in low-RH ranges (Fig. 7a, b, RH $<60 \%$ ) and ASP mostly concentrates on small SC regions when RH is less than $40 \%$ (Fig. 7a), implying that fine particles dominate the most in low-RH conditions, as also suggested by Andrews et al. (2006) and Babu et al. (2012). The correlation between ASP and SC becomes poorer with increasing RH (Fig. 7c), indicating that both fine and coarse aerosols might be equally important to the total SC.

Figure 8 shows the relationships between the SSA at $491 \mathrm{~nm}$ and extinction Ångström exponent (EAE) at $491 / 863 \mathrm{~nm}$ (Fig. 8a) as well as between SSA (863-491 nm) (short for dSSA) and EAE at 491/863 nm (Fig. 8b). Overall, SSA or dSSA to a certain degree have an anti-correlation with EAE in the urban area of Nanjing, especially the latter. Linear correlation coefficient is about -0.13 between SSA and EAE and about -0.75 between dSSA and EAE. Relationships between the SSA (or dSSA) and EAE to some extent reflect the aerosol types and sources as indicated by Russell et al. (2014), who proposed a method to identify the aerosol types based on the columnar aerosol optical proper- 


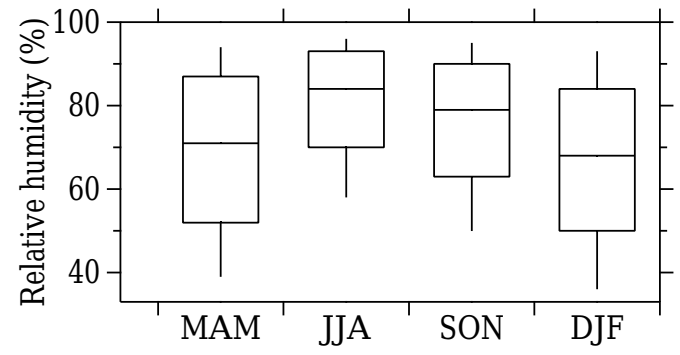

(a)

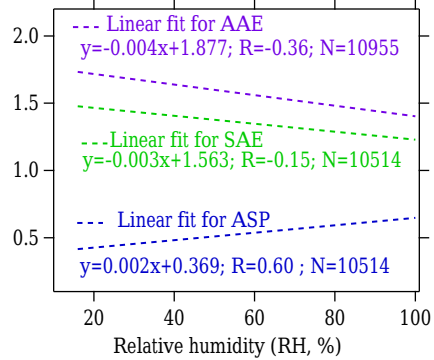

(b)

Figure 9. Seasonal variations of RH (a, \%) and linear correlations between AAE and RH (b, light blue, upper), between SAE and RH (b, green, middle) and between ASP and RH (b, deep blue, lower).

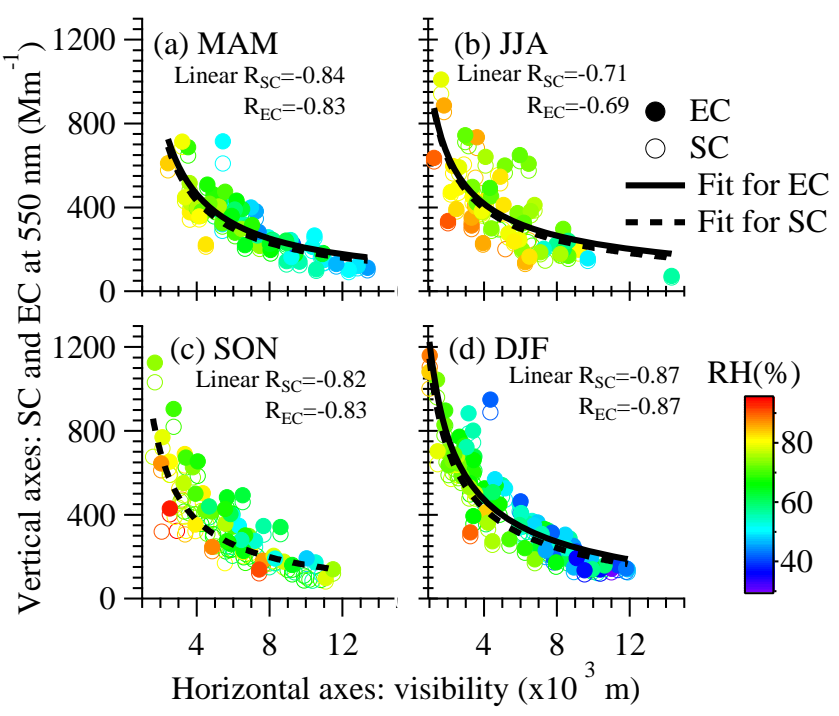

Figure 10. Relationships between SC and visibility (open cycles) and between EC and visibility (solid cycles) in different RH levels in spring (a), summer (b), autumn (c) and winter (d).

ties (including SSA, EAE and the real refractive index) from the Aerosol Robotic Network (AERONET) retrievals. They suggested the following.

1. The polluted dust aerosol had smaller EAE (near 1.0) and SSA ranged from 0.85 to 0.95 .

2. The urban aerosols had larger EAE values (around 1.4) and SSA ranges $(0.86-1.0)$ compared with the dust aerosols.

3. The biomass burning aerosol (dark type) had the largest EAE (exceeding 1.5) but smaller SSA (about 0.85).

If there were two kind of aerosols having nearly identical coordinates in SSA and EAE, further information (such as the real refractive index) should be used (Russell et al., 2014). Based on this method, the figure further implies that, in addition to local emissions, aerosols in the urban area of Nanjing might also be affected substantially by the long-distance

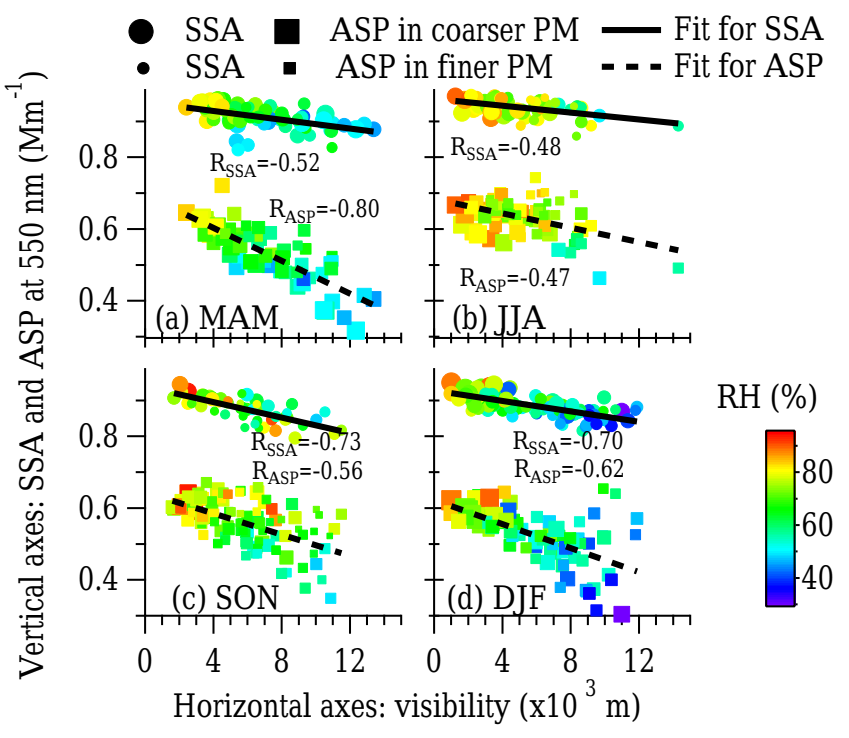

Figure 11. Relationships between SSA and visibility (solid cycles) and between ASP and visibility (solid squares) in different RH and AAE levels in spring (a), summer (b), autumn (c) and winter (d).

transported dust (or polluted dust) in spring and be influenced to some extent by biomass burning in autumn.

Atmospheric humidity has significant influences on the growth of particulate matter, subsequently affecting the sizes and absorbing/scattering abilities of the aerosols. As shown in Fig. 7a, c, high levels of SC are likely found in high RH ranges. Seasonal mean RH is largest in summer but lowest in winter (Fig. 9a). In summer, both trace gases and particulate matters have lower emission rates as suggested by Zhang et al. (2009). Furthermore, PBL height and precipitation mostly have larger values in this season than in other seasons. Thus, these three factors would result in smaller aerosol loadings in summer (such as Bsp is the smallest in this season). However, contrary to Bsp, SC in summer is larger than in spring and autumn, which might mainly result from the effects of high RH (Fig. 1c, d), although gas-to-particle transformation also contribute to SC to a certain degree in this season. Zhang et 


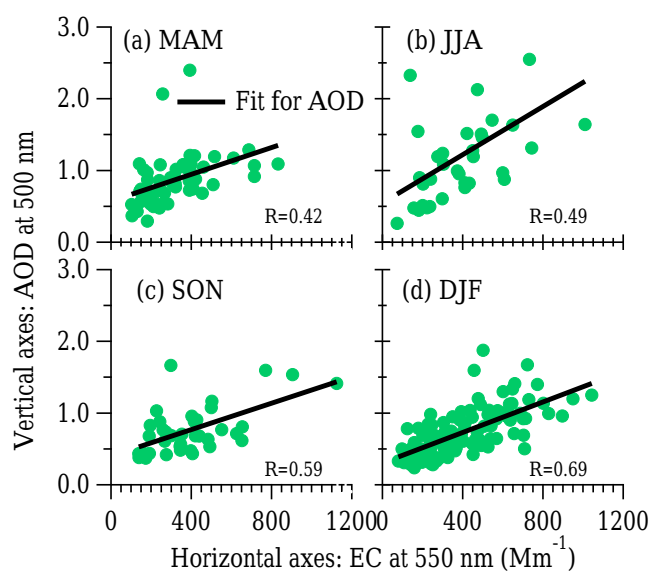

Figure 12. Relationships between surface EC at $550 \mathrm{~nm}$ and column AOD at $500 \mathrm{~nm}$ in spring (a), summer (b), autumn (c) and winter (d).

al. (2015) indicated that SC and Bsp in YRD would increase by 50 and $25 \%$ as the RH increased from 40 to $85 \%$ and the increment would become larger if there were considerable amounts of nitrate in fine particles. Nitrate in the urban area of Nanjing accounts for more than $20 \%$ (as much as sulfate) of the total $\mathrm{PM}_{2.1}$ (Zhuang et al., 2014a). RH might also affect the size of the aerosols. The smallest AAE in JJA always corresponds to the highest RH, and vice versa (Figs. $1 \mathrm{~b}$ and 9a). These results are consistent with Zhuang et al. (2014a), in which characteristics of columnar aerosol optical properties were investigated. Figure $9 \mathrm{~b}$ further shows that AAE and SAE decrease monotonically with increasing RH. The correlation between ASP and RH is opposite to that between aerosol Ångström exponent and RH. The linear correlation coefficients are $-0.36,-0.15$ and 0.6 between AAE and RH, SAE and RH, and ASP and RH, respectively, in the urban area of Nanjing. ASP and RH are highly correlated with each other, which is also reflected in Figs. 2f, 5c, d and 9a, implying that RH might have considerable influence on the aerosol forward-scattering coefficient, hence on SC. These results could be used to correct the aerosol optical parameters in numerical models for estimating the aerosol radiative forcing in east China as suggested by Andrews et al. (2006), in the hope of reducing uncertainties in such estimations.

High levels of aerosol loadings would directly affect the visibility (VIS), which is one of the factors to be concerned about in current air quality forecasting in China. The forecast accuracy of visibility or haze pollution would be increased significantly if the effects of aerosols on visibility can be figured out. Instead of the loadings of the particulate matter, the aerosol optical properties here are used when investigating the aerosol effects on VIS.

Figure 10 shows the relations between extinction coefficient (EC) and VIS and between SC and VIS by season under different RH levels. Atmospheric VIS is found to decrease exponentially with increasing EC or SC in all seasons. The lapse rate of VIS with EC or SC is much larger in spring and summer than in autumn and winter. The lower VIS always appears at higher RH ranges and vice versa. In small VIS regions (such as $<4 \mathrm{~km}$ ), VIS values are much smaller in JJA than those in the other seasons under the same SC level, implying the strong effects of RH on VIS. The effect of AAC on VIS has substantial seasonality and it is strong in SON but weak in MAM and JJA as illustrated in the fitting lines in the figure. A study on the effects of PM on VIS might be more reasonable if it used the aerosol optical properties rather than its mass concentrations. The linear correlation coefficient between EC and VIS varies from -0.69 (in JJA) to -0.87 (in DJF), and between SC and VIS, it varies from -0.71 (in JJA) to -0.87 (in DJF) in the urban area of Nanjing.

In addition to the SC or EC, the aerosol SSA and ASP also have good relationships with VIS as shown in Fig. 11, in which the effects of RH and SAE are also included (larger markers represent smaller SAE, but larger size of the aerosols). The aerosols would become coarser, less absorbing and more forward scattering to some extent with increasing $\mathrm{RH}$, which subsequently further exacerbates the deterioration of visibility in all seasons. The linear correlation coefficients vary from -0.48 (in JJA) to -0.73 (in SON) between SSA and VIS and -0.47 (in JJA) to -0.80 (in MAM) between ASP and VIS in urban Nanjing. These results additionally illustrate that the scattering aerosols are still key factors affecting the atmospheric visibility, although the absorbing aerosols might have considerable influence on VIS in some seasons (Fig. 10c). The results in this study further indicate that effects of aerosols on air quality are complex.

A comparison between surface aerosol extinction coefficient and columnar AOD is performed (Fig. 12). Differences exist between EC and AOD, although they are well correlated with each other in each season. AOD to some extent is less affected by the development of boundary layer and more affected by the transport of aerosols compared to EC at the surface. The seasonal mean EC is large, both in JJA and in DJF, while the largest AOD is only found in JJA, which is possibly related to higher boundary layer height in JJA. A lower boundary layer would lead to more aerosol accumulation at the surface thus result in its smaller column burden. These differences (high surface aerosol loadings but low AOD) have also been simulated by a regional climate chemistry model in Zhuang et al. (2011, 2013). Overall, high AOD level corresponds to large EC value in each season, implying that aerosols in the upper layers mostly come from surface emissions in urban Nanjing. In some cases, longdistance transport of aerosols might contribute significantly to the AOD as shown in Fig. 12a, in which AOD exceeds 2; meanwhile EC is found to appear in low-value ranges. The slope of the linear fitting is larger in JJA (about 0.0016) than in the other seasons (all about 0.001), indicating that for a given value of EC, AOD would be higher in JJA, possibly because of higher humidity in summer. The columnar water 
vapour in summer is about 2 to 5 times of that in the other seasons.

\section{Conclusions}

In this study, the near-surface aerosol optical properties, including aerosol scattering (SC), back-scattering (Bsp), absorption (AAC) and extinction (EC) coefficients, singlescattering albedo (SSA), scattering (SAE) and absorbing (AAE) Ångström exponent, as well as asymmetry parameter (ASP), are investigated based on the measurements with the seven-channel Aethalometer (model AE-31, Magee Scientific, USA) and three-wavelength-integrating Nephelometer (Aurora 3000, Australia) in the urban area of Nanjing.

In the urban area of Nanjing, the annual mean EC, SSA and ASP at $550 \mathrm{~nm}$ are $381.958 \mathrm{Mm}^{-1}, 0.901,0.571$, respectively. SC, which accounts for about $90 \%$ of EC, is about 1 order of magnitude larger than AAC, implying that EC to a great degree has similar temporal variation and frequency distribution to SC. Absorbing aerosol is finer than the scattering one. AAE at $470 / 660 \mathrm{~nm}$ is about 1.58 , about 0.2 larger than SAE. All of the above have substantially seasonal and diurnal variations. Both the aerosol absorption and scattering coefficients have the largest values in winter due to the higher emissions. However, SC also has higher values in summer and spring likely due to higher relative humidity (RH), efficiency of gas-to-particle transformation in summer and the effect of dust in spring, respectively. High RH in summer results in the lowest AAE and largest ASP being found and it also leads to a relatively smaller SAE, although a large number of fine scattering aerosols could be produced through intensive gas-to-particle transformation in this season. Seasonality of SSA is co-determined by AAC and SC, showing the largest value in summer and lowest value in autumn. AAC, SC, Bsp and EC have more substantial diurnal variations than SSA, AAE, SAE and ASP. Because of traffic emissions, AACs are high at morning rush hours (around 09:00 and 21:00 LT) but low in the afternoon when the boundary layer is being well developed. SC and Bsp usually peak in the early morning before sunrise (1-2 $\mathrm{h}$ earlier than AACs) and reach the bottom in the afternoon. High levels of SC and Bsp are mostly caused by accumulation of air pollution at night-time from midnight to sunrise. The diurnal variation of SSA is also dependent on AAC and SC. SSA is large after midnight and noon. AAE and SAE in the daytime are slightly larger than after midnight because both absorbing and scattering aerosols are fresher in the daytime but more aged before sunrise. ASP is related to the size of the aerosols and its diurnal variation is the opposite of SAEs but similar to Bsps.

The seasonal and diurnal observations of the aerosol optical properties are of great importance to the modelling community. In addition to the aerosol emission rates, compositions, mixing states and profiles, uncertainties of the aerosol seasonality and diurnal variations might also lead to large biases when investigating the aerosol radiative forcing and climate effects. Xu et al. (2016) showed that the aerosol direct radiative forcing would be underestimated both at the TOA and surface by 2.0 and $38.8 \mathrm{~W} \mathrm{~m}^{-2}$ if the diurnal variation were excluded. Large biases of the aerosol forcing would subsequently result in substantial uncertainties of the climate responses to the aerosol. Analyses of the seasonal and diurnal variations of the aerosol optical properties in this study to some extent are valuable to the modelling-based research on the aerosol climate effects.

Frequency analysis indicates that almost all of the aerosol optical properties follow a unimodal pattern in the urban area of Nanjing. The ranges around their averages, with different widths, account for more than $60 \%$ of the total samplings. Frequency distributions of the aerosol optical properties also have substantial seasonality. The frequency peak of a property would be more concentrated among lower/higher ranges if the seasonal mean is smaller/larger. Back trajectory analysis suggests that aerosols in Nanjing are mainly from the local and regional emissions around YRD in summer, while sources include both local emissions and transport from central and north China in winter. In JJA, aerosols are more scattering when air masses come from the East China Sea and finer if air masses come from remote areas. In DJF, AAC, SC, Bsp, SSA and ASP are low while AAE and SAE are high in urban Nanjing under the conditions of air masses being transported from remote areas. ASP variation with the clusters is consistent with RH in both JJA and DJF.

The correlation between SC and Bsp is much better than between SC and AAC in all seasons. In spring, these relationships are a little weaker than those in suburban Nanjing. ASP has a quasi-log-normal distribution with $\mathrm{SC}$ under $\mathrm{RH}$ conditions being lower than $60 \%$ and increasing monotonically with increasing SC. It would be mostly concentrated at small $\mathrm{SC}$ regions when $\mathrm{RH}$ is less than $40 \%$ because finer particles dominate under low-RH conditions. The correlation between ASP and SC becomes weaker with increasing RH, indicating that both fine and coarse aerosols might be equally important to the total SC in high RH conditions. Atmospheric humidity can significantly modulate aerosol optical properties. Due to the effects of RH in summer, the aerosol would become coarser and its forward-scattering efficiency would be stronger with increasing in RH. The linear correlation coefficients are $-0.36,-0.15$ and 0.6 between AAE and RH, SAE and $\mathrm{RH}$, and ASP and RH, respectively, in the urban area of Nanjing. Comparisons also indicate that seasonal variation of surface aerosol EC (high in JJA and DJF) is different from its columnar optical depth (AOD, high in JJA and low in DJF), even though they are closely correlated to each other within each season. Overall, high AOD level corresponding to a large EC value in each season implies that aerosols in upper layers are mostly from surface emissions. AOD would be higher in JJA than in other seasons in a condition with fixed EC, possibly due to the effects of high humidity. 
Overall, the scattering aerosols are still the key factor in affecting the atmospheric visibility (VIS), although the absorbing aerosol has considerable contributions in some seasons. The linear correlation coefficient between EC and VIS varies from -0.69 to -0.87 , close to those between SC and VIS. VIS is found to decrease exponentially with increasing $\mathrm{EC}$ or SC in all seasons. Its lapse rate along with EC or SC is much larger in spring and summer than in autumn and winter. In small VIS regions (i.e. VIS $<4 \mathrm{~km}$ ), VIS values are much smaller in JJA than in other seasons if the SC levels are the same, further indicating the strong effect of RH on VIS. The aerosol SSA and ASP could also affect VIS. Large SSA and ASP might further exacerbate the deterioration of visibility. The linear correlation coefficients between seasonal SSA and VIS varies from -0.48 to -0.73 and from -0.47 to -0.80 between ASP and VIS in the urban area of Nanjing.

\section{Data availability}

The HYSPLIT model was supplied by NOAA: http://ready. arl.noaa.gov/HYSPLIT_traj.php. The meteorological data for Hysplit are accessible from ftp://arlftp.arlhq.noaa.gov/ pub/archives/gdas1. The observed meteorological data at urban area of Nanjing are accessible from http://data.cma.cn.

Competing interests. The authors declare that they have no conflict of interest.

Acknowledgements. This work was supported by the National Key Basic Research Development Program of China (2014CB441203, 2016YFC0203303), the National Natural Science Foundation of China (41675143, 91544230, 41621005), FP7 project: REQUA (PIRSES-GA-2013-612671), and a project funded by the Priority Academic Program Development of the Jiangsu Higher Education Institutions (PAPD), the National Science Foundation of Jiangsu Provence (grant \#BE2015151). The authors would like to thank all members in the AERC of Nanjing University for maintaining instruments, and also thank the anonymous reviewers for their constructive and valuable comments on this paper. The HYSPLIT model was supplied by NOAA: http://ready.arl.noaa.gov/HYSPLIT_traj.php.

Edited by: Z. Li

Reviewed by: four anonymous referees

\section{References}

Andreae, M. O., Schmid, O., Yang, H., Chand, D., Yu, J. Z., Zeng, L. M., and Zhang, Y. H.: Optical properties and chemical composition of the atmospheric aerosol in urban Guangzhou, China Atmos. Environ., 42, 6335-6350, 2008.
Andrews, E., Sheridan, P. J., Fiebig, M., McComiskey, M., Ogren, J. A., Arnott, P., Covert, D., Elleman, R., Gasparini, R., Collins, D., Jonsson, H., Schmid, B., and Wang, J.: Comparison of methods for deriving aerosol asymmetry parameter, J. Geophys. Res., 111, D05S04, doi:10.1029/2004JD005734, 2006.

Arnott, W. P., Hamasha, K., Moosmuller, H., Sheridan, P. J., and Ogren, J. A.: Towards aerosol light-absorption measurements with a 7-wavelength aethalometer: evaluation with a photoacoustic instrument and 3-wavelength nephelometer, Aerosol Sci. Technol., 39, 17-29, doi:10.1080/027868290901972, 2005.

Babu, S., Gogoi, M., Kumar, V. H. A., Nair, V. S., and Moorthy, K. K.: Radiative properties of Bay of Bengal aerosols: spatial distinctiveness and source impacts, J. Geophys. Res., 117, D06213, doi:10.1029/2011JD017355, 2012.

Bai, H. T., Chen, Y. H., Wang, H. Q., Zhang, Q., Guo, N., Wang, S., Pan, H., and Zhang, P.: Seasonal variation of aerosol optical properties at AERONET of the semi-arid region in Loess Plateau, Arid Land Geogr., 34, 1-8, 2011.

Bellouin, N., Boucher, O., Tanré, D., and Dubovik, O.: Aerosol absorption over the clear-sky oceans deduced from POLDER1 and AERONET observations, Geophys. Res. Lett., 30, 1748, doi:10.1029/2003GL017121, 2003.

Bergin, M. H., Cass, G. R., Xu, J., Fang, C., Zeng, L., Yu, T., Salmon, L. G., Kiang, C. S., Tang, X. Y., Zhang, Y. H., and Chameides, W. L.: Aerosol radiative, physical, and chemical properties in Beijing during June 1999, J. Geophys. Res., 106, 17969-17980, 2001.

Cai, H. K., Zhou, R. J., Fu, Y. F., Zheng, Y. Y., and Wang, Y. J.: Cloud-aerosol lidar with or thogonal polarization detection of aerosol optical properties after a crop burning case, Clim. Environ. Res., 16, 469-478, 2011.

Cao, J., Wang, Q., Chow, J. C., Watson, J. G., Tie, X., Shen, Z., Wang, P., and An Z.: Impacts of aerosol compositions on visibility impairment in Xi'an, China, Atmos. Environ., 59, 559-566, 2012.

Chameides, W. L. and Bergin, M.: Soot takes center stage, Science, 297, 2214-2215, 2002.

Che, H., Zhang, X.-Y., Xia, X., Goloub, P., Holben, B., Zhao, H., Wang, Y., Zhang, X.-C., Wang, H., Blarel, L., Damiri, B., Zhang, R., Deng, X., Ma, Y., Wang, T., Geng, F., Qi, B., Zhu, J., Yu, J., Chen, Q., and Shi, G.: Ground-based aerosol climatology of China: aerosol optical depths from the China Aerosol Remote Sensing Network (CARSNET) 2002-2013, Atmos. Chem. Phys., 15, 7619-7652, doi:10.5194/acp-15-7619-2015, 2015.

Cheng, Y. F., Wiedensohler, A., Eichler, H., Su, H., Gnauk, T., Bruggemann, E., Herrmann, H., Heintzenberg, J., Slanina, J., Tuch, T., Hu, M., and Zhang, Y. H.: Aerosol optical properties and related chemical apportionment at Xinken in Pearl River Delta of China, Atmos. Environ., 42, 6351-6372, 2008.

Collaud Coen, M., Weingartner, E., Apituley, A., Ceburnis, D., Fierz-Schmidhauser, R., Flentje, H., Henzing, J. S., Jennings, S. G., Moerman, M., Petzold, A., Schmid, O., and Baltensperger, U.: Minimizing light absorption measurement artifacts of the Aethalometer: evaluation of five correction algorithms, Atmos. Meas. Tech., 3, 457-474, doi:10.5194/amt-3-457-2010, 2010.

Fan, X. H., Chen, H. B., Xia, X. A., Li, Z. Q., and Cribb, M.: Aerosol optical properties from the Atmospheric Radiation Measurement Mobile Facility at Shouxian. China, J. Geophys. Res., 115, D00K33, doi:10.1029/2010JD014650, 2010. 
Forster, P., Ramaswamy, V., Artaxo, P., Berntsen, T., Betts, R., Fahey, D. W., Haywood, J., Lean, J., Lowe, D. C., Myhre, G., Nganga, J., Prinn, R., Raga, G., Schulz, M., and Van Dorland, R.: Changes in atmospheric constituents and in radiative forcing, in: Climate Change 2007: The Physical Science Basis. Contribution of Working Group I to the Fourth Assessment Report of the Intergovernmental Panel on Climate Change, edited by: Solomon, S., Qin, D., Manning, M., Chen, Z., Marquis, M., Averyt, K. B., Tignor, M., and Miller, H. L., Cambridge Univ. Press, Cambridge, UK, 129-234, 2007.

Gong, W., Zhang, M., Han, G., Ma, X., and Zhu, Z.: An investigation of aerosol scattering and absorption properties in Wuhan, Central China, Atmosphere, 6, 503-520, 2015.

Guo, J., Deng, M., Lee, S. S., Wang, F., Li, Z., Zhai, P., Liu, H., Lv, W., Yao, W., and Li, X.: Delaying precipitation and lightning by air pollution over the Pearl River Delta. Part I: Observational analyses, J. Geophys. Res.-Atmos., 121, 6472-6488, doi:10.1002/2015JD023257, 2016a.

Guo, J., Miao, Y., Zhang, Y., Liu, H., Li, Z., Zhang, W., He, J., Lou, M., Yan, Y., Bian, L., and Zhai, P.: The climatology of planetary boundary layer height in China derived from radiosonde and reanalysis data, Atmos. Chem. Phys., 16, 13309-13319, doi:10.5194/acp-16-13309-2016, 2016b.

Guo, J. P., Zhang, X., Che, H., Gong, S., An, X., Cao, C. X., Guang, J., Zhang, H., Wang, Y. Q., Zhang, X. C., Zhao, P., and Li, X. W.: Correlation between PM Concentrations and Aerosol Optical Depth in Eastern China, Atmos. Environ., 43, 5876-5886, 2009.

He, X., Li, C. C., Lau, A. K. H., Deng, Z. Z., Mao, J. T., Wang, M. H., and Liu, X. Y.: An intensive study of aerosol optical properties in Beijing urban area, Atmos. Chem. Phys., 9, 8903-8915, doi:10.5194/acp-9-8903-2009, 2009.

Holler, R., Ito, K., Tohno, S., and Kasahara, M.: Wavelengthdependent aerosol single scattering albedo: measurements and model calculations for a coastal site near the sea of Japan during ACE-Asia, J. Geophys. Res., 108, 8648, doi:10.1029/2002JD003250, 2003.

IPCC 2013: Climate Change 2013: The Physical Science Basis. Contribution of Working Group I to the Fifth Assessment Report of the Intergovernmental Panel on Climate Change, edited by: Stocker, T. F., Qin, D., Plattner, G.-K., Tignor, M., Allen, S. K., Boschung, J., Nauels, A., Xia, Y., Bex, V., and Midgley, P. M., Cambridge University Press, Cambridge, UK and New York, NY, USA, 1535 pp., 2013.

Jacobson, M. Z.: Control of fossil-fuel particulate black carbon and organic matter, possibly the most effective method of slowing global warming, J. Geophys. Res., 107, 4410, doi:10.1029/2001JD001376, 2002.

Kiehl, J. T. and Briegleb, B. P.: The relative roles of sulfate aerosols and greenhouse gases in climate forcing, Science, 260, 311-314, 1993.

Li, C., Marufu, L. T., Dickerson, R. R., Li, Z., Wen, T., Wang, Y., Wang, P., Chen, H., and Stehr, J. W.: In situ measurements of trace gases and aerosol optical properties at a rural site in northern China during East Asian Study of Tropospheric Aerosols: An International Regional Experiment 2005, J. Geophys. Res., 112, D22S04, doi:10.1029/2006JD007592, 2007.

Li, J., Liu, X., Yuan, L., Yin, Y., Li, Z., Li, P., Ren, G., Jin, L., Li, R., Dong, Z., Li, Y., and Yang, J.: Vertical distribution of aerosol optical properties based on aircraft measurements over the Loess Plateau in China, J. Environ. Sci, 34, 44-56, 2015 a.

Li, J., Yin, Y., Li, P., Li, Z., Li, R., Cribb, M., Dong, Z., Zhang, F., Li, J., Ren, G., Jin, L., and Li, Y.: Aircraft measurements of the vertical distribution and activation property of aerosol particles over the Loess Plateau in China, Atmos. Res., 155, 73-86, 2015 b.

Li, Z., Li, C., Chen, H., Tsay, S.-C., Holben, B., Huang, J., Li, B., Maring. H., Qian, Y., Shi, G., Xia, X., Yin, Y., Zheng, Y., and Zhuang, G.: East Asian Studies of Tropospheric Aerosols and their Impact on Regional Climate (EAST-AIRC): An overview. J. Geophys. Res. 116, D00K34, doi:10.1029/2010jd015257, 2011.

Li, Z. Q., Lee, K. H., Wang, Y. S., Xin, J. Y., and Hao, W. M.: First observation-based estimates of cloud-free aerosol radiative forcing across China, J. Geophys. Res., 115, D00K18, doi:10.1029/2009JD013306, 2010.

Liao, H. and Seinfeld, J. H.: Global impacts of gas-phase chemistryaerosol interactions on direct radiative forcing by anthropogenic aerosols and ozone, J. Geophys. Res., 110, D18208, doi:10.1029/2005JD005907, 2005.

Menon, S., Hansen, J., Nazarenko, L., and Luo, Y. F.: Climate effects of black carbon aerosols in China and India, Science, 297, 2250-2253, doi:10.1126/science.1075159, 2002.

Penner, J. E., Andreae, M., Annegarn, H., Barrie, L., Feichter, J., Hegg, D., Jayaraman, A., Leaitch, R., Murphy, D., Nganga, J., and Pitari, G.: Aerosols, their direct and indirect effects, in: Climate Change 2001: The Scientific Basis. Contribution of Working Group I to the Third Assessment Report of the Intergovernmental Panel on Climate Change, edited by: Houghton, J. T., Ding, Y., Griggs, D. J., Noguer, M., van der Linden, P. J., Dai, X., Maskell, K., and Johnson, C. A., Cambridge University Press, Cambridge, UK and New York, NY, USA, 289-348, 2001.

Petzold, A., Kopp, C., and Niessner, R.: The dependence of the specific attenuation cross-section on black carbon mass fraction and particle size, Atmos. Environ., 31, 661-672, 1997.

Qian, Y., Gong, D. Y., Fan, J. W., Leung, L. R., Bennartz, R., Chen, D. L., and Wang, W. G.: Heavy pollution suppresses light rain in China: Observations and modeling. J. Geophys. Res. 114, D00K02, doi:10.1029/2008jd011575, 2009.

Qin, S. G., Tang, J., and Wen, Y. P.: Black carbon and its importance in climate change studies, Meteorol. Monogr., 27, 3-7, 2001.

Rosenfeld, D., Lohmann, U., Raga, G. B., O’Dowd, C. D., Kulmala, M., Fuzzi, S., Reissell, A., and Andreae, M. O.: Flood or drought: how do aerosols affect precipitation?, Science, 321, 5894, 13091313, 2008.

Russell, P. B., Kacenelenbogen, M., Livingston, J. M., Hasekamp, O. P., Burton, S. P., Schuster, G. L., Johnson, M. S., Knobelspiesse, K. D., Redemann, J., Ramachandran, S., and Holben, B.: A multiparameter aerosol classification method and its application to retrievals from spaceborne polarimetry, J. Geophys. Res.Atmos., 119, 9838-9863, doi:10.1002/2013JD021411, 2014.

Schmid, O., Artaxo, P., Arnott, W. P., Chand, D., Gatti, L. V., Frank, G. P., Hoffer, A., Schnaiter, M., and Andreae, M. O.: Spectral light absorption by ambient aerosols influenced by biomass burning in the Amazon Basin. I: Comparison and field calibration of absorption measurement techniques, Atmos. Chem. Phys., 6, 3443-3462, doi:10.5194/acp-6-3443-2006, 2006.

Streets, D. G., Gupta, S., Waldhoff, S. T., Wang, M. Q., Bond, T. C., and Bo, Y. Y.: Black carbon emissions in China, Atmos. Environ., 35, 4281-4296, doi:10.1016/S1352-2310(01)00179-0, 2001. 
Sun, Y. L., Wang, Z. F., Du, W., Zhang, Q., Wang, Q. Q., Fu, P. Q., Pan, X. L., Li, J., Jayne, J., and Worsnop, D. R.: Longterm real-time measurements of aerosol particle composition in Beijing, China: seasonal variations, meteorological effects, and source analysis, Atmos. Chem. Phys., 15, 10149-10165, doi:10.5194/acp-15-10149-2015, 2015.

Tao, J., Zhang, L. M., Cao, J. J., Hsu, S. C., Xia, X. G., Zhang, Z. S., Lin, Z. J., Cheng, T. T., and Zhang, R. J.: Characterization and source apportionment of aerosol light extinction in Chengdu, southwest China, Atmos. Environ., 95, 552-562, 2014.

Wang, T. J., Zhuang, B. L., Li, S., Liu, J., Xie, M., Yin, C. Q., Zhang, Y., Yuan, C., Zhu, J. L., Ji, L. Q., and Han, Y.: The interactions between anthropogenic aerosols and the East Asian summer monsoon using RegCCMS, J. Geophys. Res.-Atmos., 120, 1-20, doi:10.1002/2014JD022877, 2015.

Wang, Y., Che, H. Z., Ma, J. Z., Wang, Q., Shi, G. Y., Chen, H. B., Goloub, P., and Hao, X. J.: Aerosol radiative forcing under clear, hazy, foggy, and dusty weather conditions over Beijing, China, Geophys. Res. Lett., 36, L06804, doi:10.1029/2009GL037181, 2009.

Wang, Y., Wang, M., Zhang, R., Ghan, S. J., Lin, Y., Hu, J., Pan, B., Levy, M., Jiang, J. H., and Molina, M. J.: Assessing the effects of anthropogenic aerosols on Pacific storm track using a multiscale global climate model, P. Natl. Acad. Sci., 111, 6894-6899, 2014.

Weingartner, E., Saathoff, H., Schnaiter, M., Streit, N., Bitnar, B., and Baltensperger, U.: Absorption of light by soot particles: determination of the absorption coefficient by means of aethalometers, J. Aerosol Sci., 34, 1445-1463, doi:10.1016/S00218502(03)00359-8, 2003.

Wu, D., Mao, J. T., Deng, X. J., Tie, X. X., Zhang, Y. H., Zeng, L. M., Li, F., Tan, H. B., Bi, X. Y., Huang, X. Y., Chen, J., and Deng, T.: Black carbon aerosols and their radiative properties in the Pearl River Delta region, Sci. China D, 52, 1152-1163, doi:10.1007/s11430-009-0115-y, 2009.

Wu, D., Wu, C., Liao, B., Chen, H.,Wu, M., Li, F., Tan, H., Deng, T., Li, H., Jiang, D., and Yu, J. Z.: Black carbon over the South China Sea and in various continental locations in South China, Atmos. Chem. Phys., 13, 12257-12270, doi:10.5194/acp13-12257-2013, 2013.

Wu, Y. F., Zhang, R. J., Pu, Y. F., Zhang, L. M., Ho, K. F., and Fu, C. B.: Aerosol optical properties observed at a semi-arid rural site in northeastern China, Aerosol Air Qual. Res., 12, 503-514, 2012.

Xia, X. A., Li, Z. Q., Holben, B., Wang, P., Eck, T., Chen, H. B., Cribb, M., and Zhao, Y. X.: Aerosol optical properties and radiative effects in the Yangtze Delta region of China, J. Geophys. Res., 112, D22S12, doi:10.1029/2007JD008859, 2007.

Xiao, Z. Y., Jiang, H., Chen, J., Wang, B., and Jiang, Z. S.: Monitoring the aerosol optical properties over Hangzhou using remote sensing data, Acta Sci. Circumst., 31, 1758-1767, 2011.

Xin, J., Wang, Y., Pan, Y., Ji, D., Liu, Z., Wen, T., Wang, Y., Li, X., Sun, Y., Sun, J., Wang, P., Wang, G., Wang, X., Cong, Z., Song, T., Hu, B., Wang, L., Tang, G., Gao, W., Guo, Y., Miao, H., Tian, S., and Wang, L.: The Campaign on Atmospheric Aerosol Research Network of China: CARE-China, B. Am. Meteor. Soc., 96, 1137-1155, doi:10.1175/BAMS-D-14-00039.1, 2014.

Xu, H., Guo, J. P., Ceamanos, X., Roujean, J. L., Min, M., and Carrer, D.: On the influence of the diurnal variations of aerosol content to estimate direct aerosol radiative forcing us- ing MODIS data, Atmospheric Environment, 141, 186-196, doi:10.1016/j.atmosenv.2016.06.067, 2016.

Xu, J., Bergin, M. H., Yu, X., Liu, G., Zhao, J., Carrico, C. M., and Baumann, K.: Measurement of aerosol chemical, physical and radiative properties in the Yangtze delta region of China, Atmos. Environ., 36, 161-173, 2002.

Xu, J., Bergin, M. H., Greenwald, R., Schauer, J. J., Shafer, M. M., Jaffrezo, J. L., and Aymoz, G.: Aerosol chemical, physical, and radiative characteristics near a desert source region of Northwest China during ACE-Asia, J. Geophys. Res., 109, D19S03, doi:10.1029/2003JD004239, 2004.

Xu, J., Tao, J., Zhang, R., Cheng, T., Leng, C., Chen, J., Huang, G., Li, X., and Zhu, Z.: Measurements of surface aerosol optical properties in winter of Shanghai, Atmos. Res., 109-110, 25-35, 2012.

Yan, P.: Study on the aerosol optical properties in the background regions in the East part of China, PhD Thesis, Peking University, China, 2006.

Yan, P., Tang, J., Huang, J., Mao, J. T., Zhou, X. J., Liu, Q., Wang, Z. F., and Zhou, H. G.: The measurement of aerosol optical properties at a rural site in Northern China, Atmos. Chem. Phys., 8, 2229-2242, doi:10.5194/acp-8-2229-2008, 2008.

Yu, X. N., Ma, J., Kumar, K. R., Zhu, B., An, J. L., He, J. Q., and Li, M.: Measurement and analysis of surface aerosol optical properties over urban Nanjing in the Chinese Yangtze River Delta, Sci. Total Environ., 542, 277-291, 2016.

Zhang, L., Sun, J. Y., Shen, X. J., Zhang, Y. M., Che, H., Ma, Q. L., Zhang, Y. W., Zhang, X. Y., and Ogren, J. A.: Observations of relative humidity effects on aerosol light scattering in the Yangtze River Delta of China, Atmos. Chem. Phys., 15, 84398454, doi:10.5194/acp-15-8439-2015, 2015.

Zhang, Q., Streets, D. G., Carmichael, G. R., He, K. B., Huo, H., Kannari, A., Klimont, Z., Park, I. S., Reddy, S., Fu, J. S., Chen, D., Duan, L., Lei, Y., Wang, L. T., and Yao, Z. L.: Asian emissions in 2006 for the NASA INTEX-B mission, Atmos. Chem. Phys., 9, 5131-5153, doi:10.5194/acp-9-5131-2009, 2009.

Zhang, W., Hu, B., Chen, C. H., Du, P., Zhang, L., and Feng, G. H.: Scattering properties of atmospheric aerosols over Lanzhou City and applications using an integrating nephelometer, Adv. Atmos. Sci., 21, 848-856, 2004.

Zhang, X. Y., Wang, Y. Q., Niu, T., Zhang, X. C., Gong, S. L., Zhang, Y. M., and Sun, J. Y.: Atmospheric aerosol compositions in China: Spatial/temporal variability, chemical signature, regional haze distribution and comparisons with global aerosols, Atmos. Chem. Phys., 12, 779-799, doi:10.5194/acp12-779-2012, 2012.

Zhu, J., Wang, T., Talbot, R., Mao, H., Hall, C. B., Yang, X., Fu, C., Zhuang, B., Li, S., Han, Y., and Huang, X.: Characteristics of atmospheric Total Gaseous Mercury (TGM) observed in urban Nanjing, China, Atmos. Chem. Phys., 12, 12103-12118, doi:10.5194/acp-12-12103-2012, 2012.

Zhuang, B. L., Jiang, F., Wang, T. J., Li, S., and Zhu, B.: Investigation on the direct radiative effect of fossil fuel blackcarbon aerosol over China, Theor. Appl. Climatol., 104, 301312, doi:10.1007/s00704-010-0341-4, 2011.

Zhuang, B. L., Liu, Q., Wang, T. J., Yin, C. Q., Li, S., Xie, M., Jiang, F., and Mao, H. T.: Investigation on semi-direct and indirect climate effects of fossil fuel black carbon aerosol over China, 
Theor. Appl. Climatol., 114, 651-672, doi:10.1007/s00704-0130862-8, 2013a.

Zhuang, B. L., Li, S., Wang, T. J., Deng, J. J., Xie, M., Yin, C. Q., and Zhu, J. L.: Direct radiative forcing and climate effects of anthropogenic aerosols with different mixing states over China, Atmos. Environ., 79, 349-361, doi:10.1016/j.atmosenv.2013.07.004, 2013b.

Zhuang, B. L., Wang, T. J., Li, S., Liu, J., Talbot, R., Mao, H. T., Yang, X. Q., Fu, C. B., Yin, C. Q., Zhu, J. L., Che, H. Z., and Zhang, X. Y.: Optical properties and radiative forcing of urban aerosols in Nanjing, China, Atmos. Environ., 83, 43-52, 2014a.
Zhuang, B. L., Wang, T. J., Liu, J., Li, S., Xie, M., Yang, X. Q., Fu, C. B., Sun, J. N., Yin, C. Q., Liao, J. B., Zhu, J. L., and Zhang, Y.: Continuous measurement of black carbon aerosol in urban Nanjing of Yangtze River Delta, China, Atmos. Environ., 89, 415-424, 2014b.

Zhuang, B. L., Wang, T. J., Liu, J., Ma, Y., Yin, C. Q., Li, S., Xie, M., Han, Y., Zhu, J. L., Yang, X. Q., and Fu, C. B.: Absorption coefficient of urban aerosol in Nanjing, west Yangtze River Delta, China, Atmos. Chem. Phys., 15, 13633-13646, doi:10.5194/acp-15-13633-2015, 2015. 